\title{
Ejército y fiscalidad en la encomienda santiaguista de Montalbán (Aragón) durante la guerra de los Dos Pedros $(1356-1366)^{*}$
}

\author{
Army and Taxation in the Commandery of Montalbán (Aragón) \\ of the Order of Santiago during The War of the Two Pedros \\ $(1356-1366)$
}

\author{
MARIO LAFUENTE GÓMEZ ** \\ Sergio Martínez García***
}

ABSTRACT

\begin{abstract}
RESUMEN
A través del ejemplo de Montalbán, analizamos algunos de los problemas que afectaron al medio rural aragonés como consecuencia de la guerra de los Dos Pedros, en relación con el reclutamiento y envío de hombres armados a la frontera, la contribución en los diversos subsidios pactados en Cortes y la construcción de

defensas fortificadas. A causa de su pertenencia a la orden militar de Santiago, en la villa y sus aldeas se desarrollaron algunas particularidades a las que prestamos especial atención, como son la convocatoria por separado del comendador y de la hueste de la villa $y$, por otro lado, el reparto de los compartimentos asignados entre el brazo eclesiástico y el de las universidades reales. Asimismo, presentamos un caso excepcional de confiscación de bienes justificado por el incumplimiento de obligaciones fiscales en la Comunidad de
\end{abstract}

Through the example of Montalbán, we analyze some of the problems that afflicted the rural area of Aragon after the War of the Two Pedros: The recruitment and dispatching of armed men to the border, the contribution of subsidies previously agreed upon in the Cortes, and the construction of fortified defences. We pay special attention to certain characteristics of this town and its villages due to the fact they belonged to the Military Order of Santiago. These include summoning separately the Commander and the town levies, on the one hand, and establishing positions assigned to the ecclesiastical estate and the towns of the royal domain, on the other. Furthermore, we present an exceptional case of the confiscation of goods, subsequently sold to Montalbán, as a result of the Community of Teruel's breaching its fiscal obligations.

* Fecha de recepción del artículo: 2010-3-1. Fecha de aceptación del artículo: 2010-12-21.

** Doctor en Historia. Universidad de Zaragoza. Dirección postal: Facultad de Filosofía y Letras, Departamento de Historia Medieval, Ciencias y Técnicas Histroiográficas y Estudios Árabes e Islámicos, Calle Pedro Cerbuna, 12, 50009, Zaragoza. Correo electrónico: mariolg@ unizar.es.

*** Licenciado en Historia. Colegio Sagrado Corazón-Moncayo. Dirección postal: Calle Juan Pablo II, 58, 50009, Zaragoza. Correo electrónico: srgiomg@gmail.com. 
Teruel que, a continuación, fueron vendidos en Montalbán.

\author{
PALABRAS CLAVE \\ Guerra, Aragón, siglo XIV, Orden militar \\ de Santiago, reclutamiento, fiscalidad, \\ fortificaciones. \\ KEY WORDS \\ War, Aragon, fourteenth century, Military \\ Order of Santiago, recruitment, taxation, \\ fortifications.
}

\title{
SUMARIO
}

Introducción. 1. Servicios militares: Los hombres de la encomienda y las compañías del comendador, La hueste del concejo. 2. Servicios económicos. 3. Confiscación de bienes en aldeas de Teruel. 4. Defensa y fortificación de la villa. Conclusiones.

\section{INTRODUCCIÓN}

Montalbán fue una villa de señorío eclesiástico en la que se asentó la encomienda mayor de la orden militar de Santiago en Aragón a partir del año 1210. Ubicada en la cuenca alta del río Martín, al sur de la actual provincia de Zaragoza y al nordeste de Teruel, configuró, junto con las aldeas adscritas al entorno geográfico de su jurisdicción - Peñarroyas, Adobas, Utrillas, Escucha, Palomar de Arroyos, Castel de Cabra y Torre de las Arcas-, una entidad política lo suficientemente sólida como para tener representación en Cortes; no sólo por ser sede de la encomienda santiaguista sino también por encontrarse entre las principales villas del reino. El rey Pedro II otorgó fuero a Montalbán y sus aldeas en el año 1208, dos años antes de entregar la villa a la Orden de Santiago. Sus disposiciones, que se conservan en una ratificación firmada por Jaime II en 1225, son el cimiento sobre el que se va a ir construyendo la organización municipal, la base normativa que emana del concejo y la oligarquía local.

El recuento realizado para la recaudación de un subsidio en las Cortes de Zaragoza-Calatayud celebradas entre 1365 y 1367 contabilizó hasta 700 casas en la villa de Montalbán. Del mismo modo, el monedaje del año 1373 reconoció un total de 586 fuegos para la misma villa. Es evidente que a partir de la segunda mitad del siglo XIV el número de hogares se fue reduciendo considerablemente a causa del fuerte impacto sufrido en esta parte del territorio por los acontecimientos de la guerra de los Dos Pedros y por la marcha de una parte de la población hacia otras zo-

\footnotetext{
1 El trabajo que presentamos a continuación se integra en el programa de estudios que desarrolla el Grupo de Investigación CEMA (Centro de Estudios Medievales de Aragón) de la Universidad de Zaragoza que está dirigido por Jose Ángel Sesma Muñoz, a quien junto con Carlos Laliena Corbera agradecemos las consideraciones previas a la publicación del mismo.
} 
nas con mejores perspectivas económicas. Formaban parte de la población que habitaba la villa una discreta comunidad judía cuya aljama, a finales del trecientos, debió de estar compuesta por unas diez familias que contribuyeron en los pagos de impuestos específicos y subsidios extraordinarios hasta su desaparición en el año 1415.

Por motivos de índole económica, Montalbán y sus aldeas estuvieron en continuo contacto con la Comunidad de Teruel y el Común de Huesa. La gestión de vías, montes y bosques entre términos municipales muestra las necesidades vitales de un campesinado incipientemente ganadero que tenía en la actividad agropecuaria su principal medio de subsistencia. El cultivo de cereales, viñas y la producción de aceite completan la dedicación agrícola de la villa. Por último, una visible industria textil y una actividad minera en aumento hicieron de Montalbán un centro económico en desarrollo gracias a su posicionamiento privilegiado en la mitad sur del reino, convirtiéndose en una pieza clave que articuló una circunscripción territorial con funciones coercitivas, mercantiles y fiscales perfectamente definidas ${ }^{2}$.

A partir del verano de 1356, la villa de Montalbán y sus aldeas hubieron de involucrarse, al igual que el resto de las poblaciones aragonesas, en la defensa del reino frente al ejércio castellano. La guerra de los Dos Pedros, que se iniciaba entonces y que se iba a prolongar durante diez años, vino a dilatar el importante desgaste económico que habían supuesto para los dominios de Pedro IV las recientes campañas en el Mediterráneo - particularmente en el caso del realengo y el señorío eclesiástico-, con el agravante de que para este nuevo conflicto era necesario además desplegar una serie de medidas destinadas a proteger el propio territorio ${ }^{3}$. En ambos casos, la capacidad de respuesta de la población aragonesa no

2 Sergio MARTÍNEZ GARCÍA, La villa de Montalbán durante la baja Edad Media. Una aproximación hacia su estudio, Trabajo de DEA inédito, Universidad de Zaragoza, 2007.

${ }^{3}$ Las consecuencias económicas y sociales de la organización militar en la frontera aragonesa pueden seguirse a partir de las siguientes obras: Antonio GUTIÉRREZ DE VELASCO, «La conquista de Tarazona en la guerra de los dos Pedros (año 1357)», Cuadernos de Historia Jerónimo Zurita, 10-11 (1960), pp. 69-98; Id., «Las fortalezas aragonesas ante la gran ofensiva castellana en la guerra de los dos Pedros», Cuadernos de Historia Jerónimo Zurita, 12-13 (1961), pp. 7-39; Id., «La contraofensiva aragonesa en la guerra de los dos Pedros. Actitud militar y diplomática de Pedro IV el Ceremonioso (años 1358 a 1362)», Cuadernos de Historia Jerónimo Zurita (14-15), Zaragoza, 1963, pp. 7-30; Mario LAFUENTE GÓMEZ, La guerra de los Dos Pedros en Aragón (1356-1366). Impacto y trascendencia de un conflicto bajomedieval, Tesis Doctoral, Universidad de Zaragoza, 2009; Id., «La crisis del siglo XIV en Calatayud y sus aldeas: el factor de la guerra», Actas del VII Encuentro de Estudios Bilbilitanos, Zaragoza, 2009, t. II, pp. 109-121; «Aproximación a las condiciones de vida en Daroca y su entorno durante la guerra de los Dos Pedros (1356-1366)», Studium: revista de humanidades, 15 (2009), pp. 53-87. Para Valencia: María Rosa MUÑOZ POMER, «Preliminares de la guerra de los dos Pedros en el Reino de Valencia (1356)», Anales de la Universidad de Alicante. Historia Medieval, 1 (1982), pp. 117-134; Antonio RAMÓN PONT, «El infante don Fernando, señor de Orihuela, en la guerra de los dos Pedros (1356-1363)», Anales de Historia Medieval. Universidad de Alicante, 2 (1983), pp. 63-92; Julia CAMPÓN GONZALVO, "Consecuencias de la guerra de los dos Pedros en el condado de Denia», Anales de la Universidad de Alicante. Historia Medieval, 8 (1990-1991), pp. 57-68; y José Vicente CABEZUELO PLIEGO y Sonia GUTIÉRREZ LLORET, «La huerta de Alicante tras la guerra de los dos Pedros. Acerca de la construcción del assut nou en 1377", Anales de la Universidad de Alicante. Historia Medieval, 8 (1990-1991), pp. 6998. Y para Cataluña, en lo que respecta a la defensa de la costa: Manuel SÁNCHEZ MARTíNEZ, «Un episodio de la guerra de los Dos Pedros: la defensa costera de Cataluña en el verano de 1365", Poder 
fue homogénea, sino que se vio condicionada por varios factores, entre los que hemos de destacar especialmente dos: en primer lugar, su ubicación geográfica, ya que la proximidad y, sobre todo, la accesibilidad entre un determinado lugar y la frontera con Castilla fue determinante para las condiciones de vida de sus habitantes, circunstancia que repercutió en distinto grado sobre prácticamente toda la mitad occidental del reino; $y$, en segundo lugar, la adscripción jurisdiccional y las existencia de privilegios particulares, que influyeron en la reglamentación de las contribuciones compartidas entre los súbditos y vasallos de Pedro IV.

En el presente trabajo, intentaremos comprobar cómo la peculiar condición jurisdiccional de la encomienda de Montalbán, perteneciente a la orden militar de Santiago, determinó la trayectoria de la villa y sus aldeas durante las conflictivas décadas de 1350 y 1360, a través de su participación en el enfrentamiento con la Corona de Castilla. Para ello, nos detendremos, en primer lugar, en la aportación de efectivos al ejército del rey desde la encomienda: por una parte, a través de las convocatorias militares dirigidas por Pedro IV al comendador, en las que se convocaba a los hombres a caballo que aquél tenía la obligación de mantener a su disposición; y, por otra, mediante la hueste de peones reclamados por Pedro IV directamente al concejo de la villa. En segundo lugar, analizaremos la respuesta de la villa y sus aldeas a las solicitudes económicas de la monarquía, tanto aquellas concedidas de modo particular como las otorgadas en las asambleas de Cortes. Y, por último, presentaremos las circunstancias bajo las que se organizó la defensa y fortificación de Montalbán, especialmente en los momentos en que el avance del ejército castellano llegó a amenazar el entorno de la villa a partir de finales de 1362.

\section{SERVICIOS MILITARES}

La aportación de efectivos a los ejércitos de las monarquías hispánicas por las órdenes militares, en la baja Edad Media, estuvo basada en la disponibilidad de compañías de hombres a caballo, cuyo tamaño estaba directamente relacionado con el potencial económico de sus señoríos ${ }^{4}$. Estos lazos de dependencia, soste-

y sociedad en la baja Edad Media. Estudios en Homenaje al profesor Luis Vicente Díaz Martín, Valladolid, 2002, pp. 273-288.

4 Los estudios sobre el sentido y el funcionamiento de las órdenes militares son cuantiosos. Entre las obras generales: Carlos DE AYALA MARTíNEZ, Las órdenes militares hispánicas en la Edad Media (siglos XII-XV), Madrid, 2003; Id., «Frontera y órdenes militares en la Edad Media castellano-leonesa (siglos XII-XIII)», Studia Historica. Historia Medieval, 24 (2006), pp. 87-112; Manuel GONZÁLEZ JIMÉNEZ, «Relaciones de las órdenes militares castellanas con la Corona», Historia. Instituciones. Documentos, 18 (1991), pp. 209-222; Enrique RODRÍGUEZ-PICAVEA MATILLA, «Frontera, soberanía territorial y Ordenes Militares en la Península Ibérica durante la Edad Media», Hispania, LII/3, 182 (1992), pp. 789-909; Philippe JOSSERAND, Église et pouvoir dans la Péninsule Ibérique. Les ordres militaires dans le royaume de Castille (1252-1369), Madrid, 2004; Anthony LUTTRELL, «La Corona de Aragón y las órdenes militares durante el siglo XIV», La Corona de Aragón en el siglo XIV, VIII Congreso de Historia de la Corona de Aragón, Valencia, 1979, v. II, pp. 67-77; María Luisa LEDESMA RUBIO, Las órdenes militares en Aragón, Zaragoza, 1994. Sobre la orden de Santiago en particular: Derek W. LOMAX, La Orden de San- 
nidos por la asignación de distintos tipos de renta por el monarca, debían garantizar el mantenimiento permanente de hombres armados con la preparación suficiente como para ponerse al servicio de su señor en el momento en que fuesen requeridos. Pero junto a esta obligación de servicio, que determinaba las relaciones entre la monarquía y las órdenes, los reyes de Aragón conservaron además la posibilidad de convocar a hueste a los concejos pertenecientes a los señoríos de dichas órdenes, al margen de sus comendadores y con procedimientos similares a los desarrollados en las villas y ciudades de realengo. Esta facultad se había extendido como regalía entre los señoríos eclesiásticos - y no sólo de órdenes militares- desde la alta Edad Media, si bien los monarcas fueron renunciando a ella posteriormente, al convertir la exención de hueste y cabalgada en un privilegio de concesión habitual ${ }^{5}$. Respecto a Montalbán, al igual que ocurrió con los lugares de la orden de Calatrava y del Hospital, Pedro IV ejerció repetidamente dicha regalía en sus enfrentamientos con Pedro I de Castilla, convocando y obteniendo un servicio regular de peones movilizados directamente por el concejo.

\section{Los hombres de la encomienda y las compañías del comendador}

El potencial militar de los comendadores de Montalbán es bien conocido en términos cuantitativos, al menos, entre los últimos años del reinado de Jaime I y comienzos de la década de $1340^{6}$. A partir de las convocatorias militares emitidas desde el consejo de los diferentes monarcas, sabemos que la compañía que debía proporcionar la encomienda santiaguista osciló entre un mínimo de cinco y un máximo de veinte hombres a caballo, cuya disponibilidad estaba garantizada por el comendador. Estas cifras sitúan a la encomienda de Montalbán entre las que menos hombres pudieron aportar a las convocatorias reales, por detrás de las de Alcañiz (orden de Calatrava) y Monzón (perteneciente desde la disolución de la orden del Temple a la orden del Hospital, dentro de la castellanía de Amposta). En algunos de estos casos, se optó incluso por conmutar el reclutamiento de freires $u$

tiago (1170-1275), Madrid, 1965; Milagros RIVERA GARRETAS, «Los ritos de iniciación en la orden militar de Santiago», Acta Historica et Archaeologica Mediaevalia, 5-6 (1984-1985), pp. 111-128; José Vicente MATELLANES MERCHÁN, «La estructura de poder en la Orden de Santiago, siglos XII-XIV», En la España Medieval, 23 (2000), pp. 293-319. Y sobre la encomienda de Montalbán: Regina SÁINZ DE LA MAZA LASOLI, La orden de Santiago en la Corona de Aragón. La encomienda de Montalbán (12101327), Zaragoza, 1980; y eadem, La orden de Santiago en la Corona de Aragón (II). La encomienda de Montalbán bajo Vidal de Vilanova (1327-1357), Zaragoza, 1988.

5 En el contexto que nos ocupa, alegaron dicho privilegio los vasallos de los monasterios de Montearagón y Casbas. M. LAFUENTE, La guerra de los Dos Pedros en Aragón, p. 378.

6 El comendador se encontraba situado, según la jerarquía de la orden, inmediatamente por debajo del maestre. El cargo era ocupado generalmente por un miembro de la nobleza, quien tenía la responsabilidad de acudir a la frontera siempre que fuese convocado para la defensa del reino; de mantener un cierto número de hombres convenientemente equipados en los castillos de la orden, quienes además deberían estar vinculados a la encomienda (específicamente freires de Santiago y no seglares) y, en caso de ser convocados por el rey, deberían pasar a formar parte de su ejército. Éstas y otras obligaciones de los comendadores de Santiago están detalladas en R. SÁINZ, La orden de Santiago, pp. 4041. 
hombres de la encomienda por el pago de una cantidad económica, con la que el rey, en principio, podría costear el sueldo de una compañía de similares características ${ }^{7}$.

A partir del verano de 1356 , casi al tiempo que declaraba la guerra al rey de Castilla, Pedro IV inició la movilización militar de sus súbditos y vasallos en virtud de los distintos elementos de que disponía para ello. Las órdenes militares arraigadas en la Corona figuraron, evidentemente, entre los destinatarios de las convocatorias emitidas por el rey, en términos que vienen a reproducir el peso específico constatado para cada una de ellas hasta entonces y que, en el caso de la encomienda de Montalbán, significó el reclutamiento del máximo de combatientes vinculados a la orden, es decir, veinte hombres a caballo. Ésta es la cantidad con la que fueron convocados al ejército aragonés los dos comendadores de Montalbán contemporáneos a la guerra de los Dos Pedros: Juan Jiménez de Urrea, hasta el verano de 1358, y, posteriormente, el castellano Fernando Gómez de Albornoz. No obstante, este hecho no significa que ambos movilizaran regularmente y tuvieran a su cargo exclusivamente a veinte hombres de armas, ya que los dos comendadores gobernaron contingentes que, en muchos casos, superaron ampliamente dicha cifra.

Al hablar de la compañía del comendador de Montalbán, hemos de distinguir, pues, entre los hombres vinculados a la orden - que constituían un grupo de, como máximo, esos veinte integrantes-y todos aquellos combatientes agregados a los anteriores, que se articularon bajo el mando del comendador en virtud de sus propias relaciones vasalláticas 0 , sencillamente, debido a la necesidad de coordinar al ejército que debía defender el reino. De hecho, al hablar de la composición de las compañías en las guerras bajomedievales, hemos de tener en cuenta que la articulación de estos grupos en periodo de servicio se regía, durante la mayor parte del tiempo, por razones estrictamente operativas, de modo que bajo el mando de un único titular podían figurar hombres de armas no necesariamente vinculados a él por lazos de tipo feudal ${ }^{8}$. No obstante, y esto merece ser subrayado, las relaciones entabladas entre los hombres de armas durante los periodos de servicio militar constituyeron, independientemente de la existencia de vínculos particulares previos, un factor determinante en la continua reestructuración de las redes de parentesco y vasallaje que articulaban a los grupos nobiliarios del reino.

En este sentido, la diferencia entre los hombres de la encomienda y los situados temporalmente bajo el mando del comendador pudo ser, en determinados mo-

\footnotetext{
7 Véase Anexo: Tabla 1.

8 Este fenómeno ha sido puesto de manifiesto para las campañas napolitanas de Alfonso $\mathrm{V}$ por Jorge SÁIZ SERRANO, Caballeros del rey. Nobleza y guerra en el reinado de Alfonso el Magnánimo, PUV, Valencia, 2008. Durante la guerra de los Dos Pedros se observa un modelo similar, como muestra el caso de las compañías dirigidas por el caballero Pedro Jiménez de Samper, Mario LAFUENTE GÓMEZ, «Pedro Jiménez de Samper, un caballero de frontera al servicio de Pedro IV de Aragón (1347-1364)», La caballería y el arte de la guerra en el mundo antiguo y medieval, eds. J.E. Ruiz Doménec y R. Da Costa, Mirabilia, 8 (2008), pp. 261-298.
} 
mentos, muy importante desde el punto de vista cuantitativo. Como pauta general, hemos de señalar que si en las cartas de convocatoria el comendador es citado siempre con veinte hombres a caballo; en los albaranes de pago o en los registros de las muestras (mostres), lo encontramos ejerciendo como titular de contingentes de diversos tamaños. Veamos algunos ejemplos.

En diciembre de 1356, Pedro IV se reunió con miembros y representantes de los cuatro brazos del reino en Daroca, en unas Cortes muy poco documentadas. En ellas, los brazos prometieron aportar una serie de hombres a caballo para defender el reino, hasta hacer un total de 1.251 efectivos. El comendador de Montalbán, Juan Jiménez de Urrea, contabilizado entre los congregados por el estamento eclesiástico, se comprometió entonces a levantar veinte de esos hombres de armas, cantidad que respondía, como hemos indicado, al potencial militar de la encomienda ${ }^{9}$. A partir de entonces, las convocatorias militares se concentraron sobre todo en cuatro grandes periodos, que se corresponden con los meses de febrero a junio de 1357, 1359 y 1361, junto a todo el año de 1363 y los primeros meses de 1364, si bien en esta última fase existieron algunos intervalos. En ellas, el comendador de Montalbán siguió siendo convocado con veinte hombres a caba$110^{10}$.

Sin embargo, los albaranes conservados en los registros de Maestre Racional del Archivo de la Corona de Aragón, muestran que Juan Jiménez de Urrea ejerció como titular de un contingente de tamaño variable, que osciló, ya durante el mes de marzo de 1357, entre cinco y 27 miembros $^{11}$. Más adelante, en la primavera de 1361, el comendador Fernando Gómez de Albornoz tenía a su cargo a 33 hombres a caballo, superando ampliamente la cantidad de veinte que, en principio, debían estar vinculados a la orden ${ }^{12}$. Esta misma caracterísitica se aprecia a lo largo de

9 Así consta en las frecuentes cartas emanadas de la cancillería real con objeto de recordar y apremiar a los brazos para que pusiesen en marcha lo prometido. Archivo de la Corona de Aragón, Cancillería, registro 1379, [en adelante ACA, Can., reg.] ff. 124v-126 (1357, ene, 28. Zaragoza), $148 \mathrm{v}-149$ (1357, feb, 17. Zaragoza) y 157v-158 (1357, mar, 2. Zaragoza). En comparación con el número de combatientes asignados al resto de órdenes, el comendador de Montalbán era el de menor potencial: fray Juan Fernández de Heredia, castellán hospitalario de Amposta debía disponer de cien hombres a caballo, y el convento calatravo de Alcañiz de cuarenta. M. LAFUENTE, La guerra de los Dos Pedros en Aragón, p. 435.

10 ACA, Can., reg. 1387, ff. 67v-68 (1364, mar, 4. Uncastillo.). M. LAFUENTE, La guerra de los Dos Pedros en Aragón, p. 218. Otra convocatoria a Fernando Gómez de Albornoz, entre otros, con la finalidad de intentar recuperar Tarazona, en ACA, Can., reg. 1383, ff. 135-138 (1360, ene, 20. Zaragoza).

11 ACA, Real Patrimonio, Maestre Racional, 887, ff. 63 (1357, mar, 5. Zaragoza), f. 66 (1357, mar, 9. Zaragoza), f. 69 (1357, mar, 10. Zaragoza), ff. 70-70v (1357, mar, 11. Zaragoza), f. 71 (1357, mar, 11. Zaragoza), f. 89v (1357, mar, 27. Zaragoza). Sin indicación sobre el número de efecitivos, ibídem, f. 120 (1357, may, 6. Magallón). M. LAFUENTE, La guerra de los Dos Pedros en Aragón, p. 437. En el mismo periodo, el maestre calatravo de Alcañiz, Pedro Muñiz de Godoy, únicamente congregó a veinte de los cuarenta hombres a caballo que había prometido en Daroca. Ibídem, p. 437.

12 ACA, Real Patrimonio, Maestre Racional, 895, f. 41v (1361, may, 31. Muel). M. LAFUENTE, La guerra de los Dos Pedros en Aragón, p. 440. La compañía gobernada por el maestre de Calatrava, Pedro Muñiz de Godoy, durante los meses primaverales de 1361 alcanzó los 58 miembros, debido sobre todo a la congregación bajo su mando de hombres de caballo procedentes de las grandes Comunidades de aldeas (Teruel y en menor medida Daroca y Calatayud). Ibídem, p. 440. 
1363, gracias a los registros de varias muestras de las tropas de caballería al servicio de Pedro IV. Entre ellas, tres se corresponden con la compañía del comendador de Montalbán: en la primera, celebrada en Zaragoza en el mes de enero, comparecieron catorce hombres a caballo; en la segunda, en el mes de junio, fueron contabilizados cincuenta y dos, siendo ésta la mayor cantidad de hombres de armas documentada bajo el mando del comendador santiaguista durante toda la guerra; y en la tercera, celebrada en Barcelona en el mes de noviembre, se registraron treinta y cinco hombres a caballo ${ }^{13}$.

Averiguar la procedencia de los hombres que sirvieron en la compañía de la orden, bajo la autoridad del comendador, es una labor complicada, si bien gracias a los citados registros de muestras de hombres a caballo podemos conocer los nombres de algunos de los combatientes movilizados en 1363 y gobernados, por lo tanto, por Fernando Gómez de Albornoz. La cuestión más significativa, en este sentido, radica en el hecho de que ninguno de sus miembros fuera anotado con la mención fray, lo que permite pensar en la ausencia de freires entre los hombres de armas que sirvieron por parte de la orden de Santiago durante el citado año. De ser así, estaríamos ante un caso excepcional entre todas las compañías de órdenes militares. En efecto, a pesar de que en todas ellas la presencia de freires fue minoritaria, ya que la mayoría de sus miembros procedían bien de la baja nobleza o bien de las elites de villas y ciudades, el único caso en que la ausencia de freires sería total es el de la encomienda santiaguista de Montalbán. En este sentido, destaca especialmente la presencia, junto a Fernando Gómez de Albornoz en 1363 , de algunos miembros de tres de los linajes de la baja nobleza aragonesa con mayor implicación en las guerras del rey: Miguel de Sesé, Ramiro de Funes y Juan de Sayas. Por otro lado, hemos de mencionar el elevado número de castellanos entre los hombres gobernados por Gómez de Albornoz, algo previsible si tenemos en cuenta el origen del comendador y, particularmente, el contexto en el que había accedido al cargo. Algunos de ellos, concretamente los citados con apellido toponímico, son los siguientes: Juan Fernández de Cuenca, Juan Fernández de Molinacueva, Sancho Martínez de Cuenca, Juan Fernández de Soria y Pedro Martínez de Serón.

\section{La hueste del concejo}

En paralelo a la movilización de los hombres a caballo vinculados a la encomienda de Montalbán, sometidos dentro del ejército real a la autoridad del comendador, el concejo de la villa fue objeto de varias convocatorias remitidas por Pedro IV, en virtud del derecho de hueste y cabalgada que el rey ejercía sobre los señoríos de las órdenes militares. Los efectivos movilizados mediante esta vía fue-

13 ACA, Real Patrimonio, Maestre Racional, 2498, ff. 6-6v (1363, ene, 30. Zaragoza) y 66v-67 (1363, jun, 12. Zaragoza); ACA, Real Patrimonio, Maestre Racional, 2497, s/n (1363, nov, 24. Barcelona). M. LAFUENTE, La guerra de los Dos Pedros en Aragón, p. 445. Véase el Anexo: Tablas 2, 3 y 4. 
ron principalmente peones, tanto lanceros como ballesteros, y, a pesar de que su reclutamiento se puede documentar a lo largo de toda la guerra - con la excepción, claro está, de los periodos de paz o tregua-, las convocatorias de este tipo se concentraron en los cuatro grandes momentos citados para el caso de las compañías a caballo, es decir, durante los meses de febrero a junio de 1357, 1359 y 1361, junto al periodo 1363-1364. En todos estos casos, la responsabilidad de movilizar a la hueste de Montalbán y sus aldeas recayó en el sobrejuntero de Zaragoza, generalmente a través de alguno de sus delegados, dado que la villa pertenecía a la junta de la cabecera del reino.

A las pocas semanas de declararse la guerra, el rey negoció con los oficiales de Montalbán y sus aldeas el reclutamiento de una primera compañía de peones. La primera solicitud de Pedro IV reclamaba la considerable cantidad de quinientos hombres, cifra que, finalmente, fue rebajada hasta doscientos (cien ballesteros y otros cien lanceros) que debían ser enviados a Calatayud ${ }^{14}$. Este primer contingente debía permanecer en la frontera durante un mes y medio. De todo ese tiempo, únicamente recibirían remuneración por los quince primeros días, cuando a cada combatiente le fueron asignados 20 sueldos jaqueses en total. Durante el mes siguiente, según una orden emitida directamente por el rey, deberían servir a sus propias expensas. Este procedimiento, sin embargo, fue replanteado muy pronto, fruto de unas nuevas negociaciones entre el rey y los oficiales de la villa, de manera que el tiempo total de servicio se redujo a un mes: quince días remunerados y otros quince sin sueldo. Al finalizar el servicio, los doscientos peones deberían regresar a la villa y ser reemplazados ${ }^{15}$.

Las convocatorias a la hueste de Montalbán continuaron en los años siguientes $^{16}$ hasta que, en marzo de 1360, la cantidad de hombres demandados se incrementó hasta trescientos. En aquella, dirigida a varias villas y ciudades aragonesas importantes desde el punto de vista demográfico y económico, se solicitaba un total de 5.200 hombres a pie ${ }^{17}$. Cada una de las villas y ciudades convocadas, sin duda, negociaría posteriormente un descenso en el número de hombres asignados, entre ellas Montalbán, cuya contribución seguramente continuaría en torno

14 «E si podets haver D homens de Muntalba, seguns que us havem escrit, qu'els haiats, sino CCCC o CCC, o al menys qu'en haiats CC, segons lo pact que havets fet». ACA, Can., reg. 1151, f. 30 (1356, nov, 12. Muel); ACA, Can., reg. 1149, f. 30v (1356, nov, 12. Muel); ACA, Can., reg. 1149, f. 28 (1356, nov, 16. Muel).

15 ACA, Can., reg. 1379, ff. 89-89v (1356, dic, 16. Daroca). La convocatoria inicial del rey, en la que les obligaba a pasar un mes sin recibir sueldo. ACA, Can., reg. 1379, f. 85 (1356, dic, 6. Calatayud).

16 Algunas de aquellas convocatorias que, bajo distintas fórmulas, se dirigieron a todos los lugares y personas del reino, en ACA, Can., reg. 1383, ff. 78-78v (1359, sep, 7. Barcelona); ACA, Can., reg. 1383, ff. 139-142v y 144-144v (1360, feb, 6. Zaragoza).

17 El reparto de esos 5.200 hombres se estableció de la siguiente forma, Zaragoza debería aportar 1.000; Daroca, 2.000; Calatayud, 2.000; Ejea, 200; Tauste, 150; Montalbán, 300; Alcañiz, 400; y La Almunia, 150. Los encargados de hacerla cumplir eran los justicias o los sobrejunteros de cada lugar, lo que a falta de otros datos nos permite suponer que en las citadas cifras se incluía a gentes de aldeas o, en el caso de las cabezas de sobrejunterías, de otros lugares ubicados en su circunscripción. ACA, Can. reg. 1383, ff. 158-159 (1360, mar, 17. Borja). M. LAFUENTE, La guerra de los Dos Pedros en Aragón, p. 424. 
a los doscientos peones aportados hasta entonces. Más adelante, en la primavera de 1364, el número de integrantes de la hueste de Montalbán se redujo hasta 140, de los cuales veinte ballesteros fueron destinados permanentemente en el castillo de Visiedo ${ }^{18}$.

La regularidad de las convocatorias y el tamaño de las compañías movilizadas nos permiten afirmar que el servicio ofrecido por la hueste de Montalbán supuso un coste demográfico relativamente acusado para la villa, ya que, a pesar de las continuas negociaciones entre el monarca y los oficiales del concejo, la cantidad mínima de peones movilizados se mantuvo en una cifra importante, en torno a los doscientos hombres. Podemos suponer que, por entonces, la villa contaba con una cifra superior a los 568 fuegos que marca el monedaje de 1373. Con estas referencias sobre el número de hogares que a mediados del siglo XIV podían contarse en Montalbán, estaríamos ante una solicitud de, como máximo, un hombre por fue$\mathrm{go}^{19}$, medida bastante frecuente entre las instrucciones emitidas desde la dirección del ejército ${ }^{20}$.

A pesar de ejecutarse en momentos puntuales, la obligación de reclutar contingentes armados suponía una carga notable para los concejos. Las actas de Cortes, por ejemplo, dan muestra de ello, al incluir regularmente algún capítulo orientado a limitar este tipo de servicios ${ }^{21}$. De hecho, tanto en la guerra de los Dos Pedros como en los discontinuos enfrentamientos con Castilla que salpicaron la década siguiente, la necesidad de defender el reino supuso la convocatoria y la negociación permanente entre el rey y los concejos fronterizos para movilizar hombres armados, cuyo coste corría habitualmente por cuenta de sus propios vecinos $^{22}$. La composición de estas huestes en las guerras con Castilla es difícil de

18 ACA, Can., reg. 1196, f. 28 (1364, abr, 20. San Mateo).

19 José Ángel SESMA MUÑOZ, «Movimientos demográficos de largo recorrido en el Aragón meridional (1200-1500)», La población de Aragón en la Edad Media (siglos XIII-XV). Estudios de demografía histórica, eds. J. A. Sesma Muñoz y C. Laliena Corbera, Zaragoza, 2004, pp. 223-280.

20 Las solicitudes de combatientes a partir de criterios estrictamente proporcionales al número de fuegos e incluso a la cantidad de hombres hábiles existentes en cada población fue habitual ya en la baja Edad Media, si bien no se aplicó sistemáticamente hasta el siglo XVI, evolucionando posteriormente hasta desembocar en el sistema de quintas. Durante la guerra de los Dos Pedros, encontramos referencias de este tipo a partir de 1361. M. LAFUENTE, La guerra de los Dos Pedros en Aragón, p. 425. Véanse, para la época moderna, las referencias incluidas en Enrique SOLANO CAMÓN, Poder monárquico y Estado pactista (1626-1652): Ios aragoneses ante la Unión de Armas, Zaragoza, 1987. Sobre el origen del sistema de quintas, Cristina BORREGUERO BELTRÁN, El reclutamiento militar por quintas en la España del siglo XVIII. Orígenes del servicio militar obligatorio, Valladolid, 1989.

21 Sirva de ejemplo la condición puesta, durante las Cortes celebradas en Cariñena en el verano de 1357, a la concesión de setecientos hombres a caballo que durante dos años debían defender el reino: que «no pueda haver huest, cavalgada ni exercito, que eran ciertos drechos antigos a cuyos appellidos eran todos obligados a salir e servir, [...] sino en caso que el senyor rey quiera dar batalla, o sitiar algun lugar, o perseguir algun delinquente, subdito suyo, por justicia». Jose Ángel SESMA MUÑOZ y Esteban SARASA SÁNCHEZ, Cortes del Reino de Aragón (1357-1451). Extractos y fragmentos de procesos desaparecidos, Valencia, 1976, p. 30.

22 El servicio militar de las huestes de peones reclutadas para la defensa del reino, durante la guerra de los Dos Pedros, aunque no fuera pagado por el rey, tampoco era gratuito. Los concejos debían correr con el coste que suponía el salario de los hombres movilizados, lo que signifacaba el reparto de su coste entre las unidades fiscales de cada población. En este punto, sin embargo, la falta de documentación 
rastrear, dado que, hasta el momento, no hemos localizado ninguna nómina de integrantes de una hueste municipal, ni para Montalbán ni tampoco para ninguna otra población del reino, correspondiente a las décadas de 1350 y $1360^{23}$. Sin embargo, las fuentes disponibles sí permiten elaborar algunas pautas comunes en lo que respecta a su formación y características de su servicio, que pasamos a resumir a continuación a partir del caso que nos ocupa.

En primer lugar, como hemos indicado anteriormente, hay que tener en cuenta que el cupo de hombres a movilizar por cada concejo - o cualquier otra otra entidad jurídica- era el resultado de una negociación iniciada por las autoridades locales al recibir la primera solicitud de hombres por parte del rey, a través de alguno de sus delegados. Este hecho nos obliga a ser extremadamente críticos con los datos disponibles en los registros de Cancillería, que constituyen la fuente principal para documentar el fenómeno, ya que en aquellos predominan las convocatorias emitidas por el consejo del rey, en las que se reclaman unas cantidades que sin duda iban a ser rebajadas posteriormente.

Una segunda característica común a todos los lugares tanto de realengo como de órdenes militares -especialmente a aquellos situados en la frontera con Castilla o, como Montalbán, en alguna de las vías de comunicación entre la zona fronteriza y Zaragoza - es la integración mayoritaria en la hueste de vecinos y habitantes de cada municipio. Más allá del reclutamiento de algunos hombres en poblaciones más o menos próximas, los concejos aragoneses no contrataron compañías foráneas para resolver sus necesidades defensivas a mediados del siglo XIV y, de hecho, es probable que no llegaran a hacerlo durante toda la baja Edad Media. El levantamiento de estos contingentes se hacía, pues, contando con los varones de cada población considerados físicamente hábiles para el combate, que serían escogidos posteriormente bien mediante su reclutamiento voluntario en una taula d'acordament o bien mediante fórmulas coercitivas, como el sorteo o el reclutamiento forzoso.

no nos permite definir qué ocurría con los grupos privilegiados. No obstante, es probable que en estos casos se impusiera el objetivo de la defensa común y, al igual que ocurría con la construcción de las murallas, se obligara también a contribuir a clérigos y nobles. En julio de 1363, por ejemplo, los oficiales de Montalbán hubieron de responder de una falta en el envío del salario a la hueste de la villa, ya que se habían desentendido de dicha obligación una vez satisfecha la cantidad equivalente a un mes de servicio. ACA, Can., reg. 1185, ff. 242-242v (1363, jul, 3. Campos de Burriana).

${ }^{23}$ En cambio, las nóminas de combatientes a pie, especialmente ballesteros, son relativamente frecuentes para los conflictos mediterráneos, al ser incluidas entre la documentación generada por los delegados del rey encargados de la administración de la armada. Por ello, las campañas contra la flota genovesa en la primera mitad de la década de 1350 y, especialmente, la dirigida por Pedro IV para someter la rebelión del Juez de Arborea, Mariano IV, en 1354, en el contexto inmediatamente anterior a la guerra de los Dos Pedros, han sido estudiados también desde el punto de vista de los contingentes de peones movilizados en los Estados de la Corona de Aragón. Véanse al respecto las conclusiones aportadas por Mario ORSI LÁZARO, "Vaguerosos e malendrins y ballesters bons e bé atreçats. Notas sobre la infantería de Pedro el Ceremonioso en una armada real a Cerdeña (1354)", Actas del IV Simposio In ternacional de Jóvenes Medievalistas de Lorca (2008), ed. Juan Francisco Jiménez Alcázar, Murcia, 2009, pp. 187-202; y Andrés DÍAZ BORRÁS, «El vicealmirante Berenguer de Ripoll y la organización de su escuadra corsaria antigenovesa a mediados del siglo XIV", El poder real en la Corona de Aragón (siglos XIV-XVI), XV Congreso de Historia de la Corona de Aragón, t. I, v. 3o, pp. 79-92. 
El tercer aspecto a tener en cuenta es la posibilidad de eludir el servicio militar en caso de cumplirse ciertas condiciones, incluidas entre los fueros del reino en la época de Jaime $\mathrm{I}^{24}$, a las que se iban añadiendo muchas más en virtud de las frecuentes reclamaciones dirigidas a la cancillería regia tanto por los concejos como por particulares. Así, varios vecinos de Montalbán consiguieron ser liberados por el rey de la obligación de participar en la hueste de la villa con el pretexto de su dedicación al ejercicio de los cargos concejiles. En abril de 1361 el justicia, los jurados y los hombres buenos de la villa recibieron una respuesta de la Cancillería del rey, por medio de la cual aquellos que detentaban los cargos de gobierno en la villa y sus aldeas eran excusados de acudir con el ejército a las fronteras del reino; y, diez días después, recibían otra carta en la que se les autorizaba a enviar a otros hombres en su lugar en caso de que ya hubieran sido obligados a enrolarse en la compañía. La lista de exentos comienza por el justicia, Nicolás Benedí, y continúa con la enumeración de los jurados, notarios y el resto de oficios de la administración y el gobierno locales ${ }^{25}$.

Y por último, cabe destacar que la aplicación de las demandas regias sobre la movilización de la hueste local presenta, en el caso de Montalbán, algunas actitudes y ciertos patrones de conducta comunes a otras partes del reino, principalmente las zonas de frontera. En este sentido, el mantenimiento de un contingente por cuenta del concejo chocó con una fuerte resistencia de los vecinos en la propia villa, con el permanente problema de las deserciones y con la incompetencia militar de sus integrantes ${ }^{26}$. Esta actitud esquiva hacia la conscripción se percibe, por ejemplo, en el progresivo endurecimiento de las sanciones incluidas en los textos

24 Según los fueros de Aragón: «En estos casos cuantos tienen que ir al ejército quedan excusados, a saber: si están enfermos, si las esposas están de parto, si se han trasladado a otra tierra o a otra villa y no oyeron al pregonero, si el padre, la madre o la esposa están a la vista de la muerte, si tienen permiso del Justicia del lugar para permanecer. Pero cualquiera que fuera de estos casos ose faltar al ejército o deje de enviar a un hombre en su lugar, pague al rey sesenta sueldos de multa». Expediciones. 251 b (en otras f. 26). Jaime Primero. En Huesca, 1247. Pascual SAVALL Y DRONDA y Santiago PENÉN Y DEBESA, Fueros, observancias y actos de corte del reino de Aragón, ed. Facsimilar, Zaragoza, 1991, p. 140.

${ }^{25}$ Los vecinos citados y sus cargos u oficios son los siguientes: Nicolás Benedí, justicia; Pedro Martín de la Torre, jurado; Juan Buey, procurador de la villa; Juan Guiralt, escribano de la Corte; Domingo Martín, administrador de los molinos; Sancho de Altabás y Miguel Navarro, recaudadores de la pecha; Esteban de Margelina, Miguel Burriel, Domingo Caballero y Pedro Entrovita, recaudadores del caballaje; Pedro Martínez de la Blanca y Sancho Pérez de Obón, notarios; Pedro Martín, herrero; Sancho de Obón, guardián de las medidas; Martín de Obón, baile de la villa; Pedro Margens, viñatero; y Domingo Ballestero, carnicero. Además, se enumeran otros sin especificar sus profesiones: Juan Navarro, Sancho el Corral (mayor), Sancho de Altabás (mayor), Lázaro de Luecana, Domingo Conchel, Pedro García de Alberite, Sancho de Altabás (menor), Pascual Lázaro, Domingo Vicente, Juan Grasida, Miguel de Conchel, Domingo Losiella, y Juan de Losiella. ACA, Can., reg. 1176, f. 53 (1361, abril, 13. La Almunia), 60v (1361, abr, 23. Calatayud) y $103 v$ (1361, may, 4. Terrer). Además, prácticamente al mismo tiempo fue exento del servicio Guillermo d'Avui, vecino de la villa, con la mediación del comendador. ACA, Can., Reg. 1173, ff. 19v-20 (1361, may, 8. Calatayud). S. MARTíNEZ, La villa de Montalbán durante la baja Edad Media, pp. 127-129.

${ }^{26}$ Sobre el cumplimiento de las obligaciones derivadas de la organización militar del reino en esta época, Mario LAFUENTE GÓMEZ, “Comportamientos sociales ante la violencia bélica en Aragón durante las guerras con Castilla (1356-1375)", Historia. Instituciones. Documentos, 35 (2008), pp. 241-268. 
de los pregones (cridas), que eran emitidos por el rey y publicados bien por medio de sus delegados o bien por alguno de los oficiales del concejo a quien se dirigían. Así, por ejemplo, el rechazo a ejecutar el contenido de una de estas órdenes, recibida en Montalbán, junto a otros muchos lugares del reino, a comienzos de 1357, provocó enseguida la insistencia del rey y, poco después, la imposición de fuertes represalias ${ }^{27}$. La solución pasó entonces por el envío a la villa y sus aldeas de un portero, Martín Pérez de Urriés, con el encargo de recorrer además los lugares pertenecientes a las órdenes del Hospital y de Calatrava, para asegurarse de que no quedasen en ellos hombres con obligaciones militares. En caso de que quedase alguno, y no estuviese excusado por su edad o por enfermedad, debería apresarlo y enviarlo al rey para ser castigado ${ }^{28}$.

En relación con las estrategias empleadas por la población para eludir estas cargas, hemos de mencionar la apelación frecuentemente empleada en la que se afirmaba una escasez prácticamente absoluta de hombres en el lugar. En efecto, se trata de un argumento poco verosímil, especialmente en lugares relativamente bien poblados como Montalbán. A mediados de marzo de 1357, sin embargo, el propio comendador había comunicado este inconveniente al rey, a fin de obtener su autorización para enviar a una parte de la hueste de la villa al castillo, en lugar de hacer salir a todos sus integrantes hacia la frontera ${ }^{29}$.

Por otro lado, los problemas de insubordinación y abandono de la frontera por los miembros de las huestes formaron parte de la cotidianeidad del ejército, como demuestra, de nuevo, la insistencia en las órdenes dirigidas a Juan Jiménez de Urrea, comendador de Montalbán y capitán en el entorno del Moncayo entre 1357 y $1358^{30}$. Entre los contingentes puestos bajo su mando se encontraban, en aque-

27 ACA, Can., reg. 1379, ff. 145v-146v (1357, feb, 15. Zaragoza). En otra de las convocatorias, dirigida a las autoridades de Montalbán, se especifica no sperando padre a fillo ni fillo a padre. ACA, Can, reg. 1152, f. 149v (1357, abr, 13. Calatayud).

28 ACA, Can., reg. 1379, ff. 168v (1357, mar, 9. Zaragoza). Vid. M. LAFUENTE, «Comportamientos sociales ante la violencia», p. 247.

29 «Las gentes de la qual villa dezides que son en Alagon e que no ha fincado X ombres en la dita vi$\mathrm{Ila}$, por que nos demandavades que vos feziessemos carta que podiessedes prender pora guarda de la dita villa e castiello de Montalban XL o a lo menos XXX ombres d'aquellos que son en la huest de Montalban; ond vos respondemos que com la dita villa e castiello de Montalban sea en tal lugar que es sin periglo, por esto quant ad agora havemos por bien que la dita huest de Montalban finque sin de partir o prender algunos d'ellos». ACA, Can., reg. 1151, f. 101v (1357, mar, 15. Zaragoza).

30 ACA, Can., reg. 1149, f. 93 (1357, mar, 13. Zaragoza). El comendador de Montalbán estuvo encargado de dirigir las huestes que, desde distintos puntos del reino, se congregaron en la frontera del Moncayo durante los primeros meses de la guerra, entre ellas las de la encomienda. ACA, Can., reg. 1381, f. 11 (1357, mar, 28. Zaragoza). A comienzos de 1357, llegaron a la cancillería regia noticias de que muchos de estos hombres estaban abandonando la frontera, por lo que desde aquella se emitieron varias órdenes dirigidas al comendador para que investigara el motivo por el cual se habían otorgado aquellas licencias y de quién había sido responsabilidad: «E d'esto a la mas antes que podades nos fagades saber la verdat del feyto que se son feytas estas gentes, ni si las havedes vos licenciados o otri por tal que podamos saber a colpa de qui se son ydas tantas gentes». ACA, Can., reg. 1381, f. 11r-11v. (1357, mar, 28. Zaragoza). Otros de los problemas que encontró en ACA, Can., reg. 1381, ff. 13v-14 (1357, mar, 29. Zaragoza); ACA, Can., reg. 1150, ff. 267v-268 (1357, may, 1. Épila); y ACA, Can., reg. 1160, ff. 53v-54 (1358, jun, 25. Barcelona). «Siquiere los de cavallo siquiere los de pie que son en Alagon son tan mala gent que no quieren ir ni exir con el dito comendador, antes dizen a su guisa sin toda obe- 
llos momentos la hueste de peones de Montalbán y, debido a las frecuentes faltas constatadas, el rey terminó por corregir las instrucciones que preveían el castigo de los desobedientes por la imposición de penas pecuniarias. Por ello, el comendador fue autorizado para cobrar una cantidad de dinero en redención de dicho deber a aquellos hombres que, estando en condiciones de acudir en hueste, no lo hiciesen. El importe a cobrar quedaba al arbitrio del comendador, quien debería entregar lo recaudado por ello a uno de los tesoreros del rey ${ }^{31}$.

Generalmente, aquellos lugares que optaban por no movilizar compañías de peones al recibir las convocatorias del rey procedían a negociar el pago de una cantidad económica, que solía fijarse en unos 60 sueldos jaqueses por cada hombre solicitado, lo que les eximía del servicio durante al menos un mes. Sin embargo, este procedimiento se observó de forma desigual, de modo que en los lugares más próximos a la frontera predominó la necesidad de armar a las huestes, mientras que en las zonas del interior del reino la insistencia en este sentido fue más esporádica. En la práctica, la sustitución del servicio por una cantidad económica, por un lado, y la imposición de sanciones pecuniarias a aquellos concejos que no proporcionaban peones, por otro, fueron dos fenómenos paralelos que tenían una consecuencia común, como era el pago de una cantidad económica tasada, además, mediante criterios similares.

Respecto a Montalbán y su entorno predominó la demanda de hombres armados durante toda la guerra de los Dos Pedros y también durante los años inmediatamente siguientes, hasta que en 1375 la paz de Almazán vino a relajar la actividad militar en la mitad occidental del Aragón. Por ello, las faltas a este tipo de convocatorias debían ser compensadas mediante el pago de multas. Un caso representativo y bien documentado es la incomparecencia general ante la convocatoria transmitida por García de Celum, sobrejuntero de Zaragoza, encargado de reclutar y enviar a unos setenta hombres de la sobrejuntería a Montalbán, con el fin de colaborar en su defensa. A finales de marzo de 1366, semanas antes de que comenzase la marcha de los castellanos de las zonas que tenían ocupadas, Pedro IV recordaba a García de Celum dicha orden y le hacía saber que García López de Sesé, capitán en la villa y encargado de recibir a los hombres armados y dirigirlos, le había informado de que sólo acudieron algunos de Alcañiz, Alcorisa y Alloza. Por ello, con objeto de asegurar la defensa de la villa, el rey ordenó que en aquellos lugares negligentes se cobrase la cantidad equivalente al salario que deberían haber percibido los peones ausentes, que ascendía a 60 sueldos jaqueses por persona durante el mes que debían haber servido (2 sueldos diarios). Se trataba, pues, de la sustitución del servicio armado por una redención económica, medida que no su-

diencia». ACA, Can., reg. 1151, ff. 101-101v (1357, mar, 15. Zaragoza). El problema de las deserciones suele formar parte de los aspectos abordados en los estudios dedicados a los ejércitos en campaña. Véase, por ejemplo, Christopher ALLMAND, «Le problème de la désertion en France, en Angleterre et en Bourgogne à la fin du Moyen Âge», Guerre, pouvoir et noblesse au Moyen Âge. Mélanges en I honneur de Philippe Contamine, eds. J. Paviot y J. Verger, París, 2000, pp. 31-41.

31 ACA, Can., reg. 1381, ff. 63v-64v (1357, jun, 27. Zaragoza). 
ponía entonces una circunstancia excepcional y que, en esta ocasión, se resolvió mediante la fórmula de sanción ${ }^{32}$. Por otro lado, el alto índice de redenciones económicas (en torno a ocho de cada diez solicitudes) nos vuelve a poner en la pista de las resistencias ante la obligación ocasional de prestar cualquier tipo de servicio armado.

\section{SERVICIOS ECONÓMICOS}

La financiación del despliegue militar dirigido por Pedro IV para defender sus Estados absorbió, entre 1356 y 1366, importantes cantidades de capital, que fueron redistribuidas según las condiciones pactadas entre el monarca y aquellas elites capacitadas para intervenir en la reglamentación de la fiscalidad real extraordinaria. En este sentido, el primer concepto que proporcionó ingresos a la administración real fue la redención de las prestaciones personales de hueste y cabalgada, en aquellos lugares que no habían sido exentos mediante privilegios particulares en el pasado. Las convocatorias de este tipo estaban justificadas en la necesidad de combatir para defender la integridad territorial del reino, si bien su ejecución fue muy desigual. Como vimos en el apartado anterior, la particular condición jurisdiccional de la encomienda de Montalbán permitió a Pedro IV solicitar el servicio de un contingente de peones reclutados entre la villa y sus aldeas, que fue mantenido con cierta regularidad durante toda la guerra. Por lo tanto, podemos afirmar que los representantes de Montalbán no negociaron en ningún momento la redención económica del servicio personal, aunque sí intentaron reducir el número de efectivos que debían enviar a la frontera. No obstante, este hecho no significa que la prestación fuese gratuita, ya que los miembros de la hueste recibían un salario, cuya financiación debía ser asumida por todas las unidades fiscales de la villa y sus aldeas, a través de los instrumentos de la fiscalidad local.

Pero, sin duda, el eje de la estrategia seguida por el rey en estos primeros meses del conflicto consistió en reproducir el modelo empleado hasta entonces en los conflictos mediterráneos, basado en la solicitud de subsidios a las aljamas, los vasallos de señorío eclesiástico y, sobre todo, a las villas y ciudades de realengo ${ }^{33}$.

32 La convocatoria se había emitido el 24 de septiembre de 1365, desde Zaragoza, y la muestra en la que se comprobó la ausencia de la mayor parte de los convocados se celebró el 8 de octubre de 1365 La lista de cantidades impuestas a cada lugar figura en un memorial adjunto y son las siguientes: Monroyo y su tenencia, 600 sueldos; Cantavieja y su bailía, 480 sueldos; Castellote y su bailía, 360 sueldos; Maella, 300 sueldos; Alcañiz, 240 sueldos; La Fresneda, 240 sueldos; Calaceite, 240 sueldos; Rueda y sus lugares, 240 sueldos; Molinos, 240 sueldos; Caspe, 180 sueldos; Cretas, 120 sueldos; Chiprana, 120 sueldos; Samper de Calanda, 120 sueldos; Castelserás, 60 sueldos; Alloza, 60 sueldos; Lidón, 60 sueldos; y Nonaspe, 60 sueldos. Total: 3.720 sueldos jaqueses por la redención de 62 hombres. ACA Can., reg. 1214, ff. 62v-63v (1366, mar, 31. Zaragoza).

33 Los mecanismos fiscales empleados para la financiación de los conflictos mediterráneos son mejor conocidos para Cataluña que para el resto de la Corona de Aragón. No obstante, se trata de una línea de investigación vigente que tiende a ser planteada, cada vez más, desde una perspectiva comparada. Véanse, entre otros, algunos de los trabajos más recientes del profesor Manuel SÁNCHEZ MARTÍNEZ «Corts, parlaments y fiscalidad en Cataluña: las profertes para las guerras mediterráneas (1350-1356)», 
Así, entre el comienzo de la guerra en el verano de 1356 y el establecimiento de una paz temporal en Tudela, en julio del año siguiente, el sistema de financiación del ejército vino a prolongar la serie de servicios negociados en los años inmediatamente anteriores, que habían sido destinados a costear la campaña dirigida por el rey contra la rebelión del Juez de Arborea, en Cerdeña. En este contexto, varios delegados del rey fueron negociando directamente con los representantes de algunas entidades de realengo, con los titulares de algunos señoríos eclesiásticos y con prácticamente todas las aljamas aragonesas. El producto obtenido de estos conceptos debía ser administrado por oficiales designados por el rey y empleado, en su mayor parte, para satisfacer el salario correspondiente al servicio militar de las compañías lideradas por los ricos hombres y caballeros del reino.

La ejecución de estas demandas en la encomienda de Montalbán se llevó a cabo en dos contextos diferentes: por un lado, los procedimientos de negociación entre los delegados del rey y las aljamas aragonesas y, por otro, los llevados a cabo con el comendador, como señor de la villa y sus aldeas. En lo que respecta a las aljamas, entre 1356 y 1357 se sucedieron dos grandes fases de negociación, que se concretaron en sendos ciclos fiscales. En el primero de ellos, resuelto en noviembre de 1356, participaron treinta entidades (entre aljamas de judíos, aljamas de musulmanes y judíos francos), que se comprometieron a pagar un total de 116.000 sueldos jaqueses, si bien finalmente sólo pudieron ser recaudados 35.000 . El comportamiento de la aljama de judíos de Montalbán reproduce esta pauta de modo significativo, ya que de los 2.000 sueldos prometidos a los oficiales del rey, únicamente pudieron ser recaudados $300^{34}$. Una vez satisfecho este servicio, en febrero de 1357 se puso en marcha de nuevo la maquinaria recaudatoria y los delegados del rey debían obtener, a priori, 46.700 sueldos jaqueses entre prácticamente todas las aljamas que habían participado anteriormente, aunque desconocemos qué porcentaje llegó a ser efectivamente recaudado. En esta ocasión, los judíos de Montalbán prometieron 700 sueldos (1,5\% del total). Tanto en el primero como en el segundo de estos dos ciclos, el peso específico de la la aljama de judíos de Montalbán fue muy modesto, situándose respectivamente en el decimocuarto y el decimoquinto lugar dentro del conjunto ${ }^{35}$.

En el segundo de los ámbitos citados, las negociaciones entre los oficiales de Pedro IV y el comendador de Montalbán dieron lugar, al menos, a un servicio económico para este periodo, concedido a principios de marzo de 1357 y tasado

El poder real en la Corona de Aragón (siglos XIV-XVI), XV Congreso de Historia de la Corona de Aragón, Zaragoza, 1997, t. IV, pp. 251-272; Id., «El realengo catalán en la financiación de la campaña a Cerdeña de 1356», Acta Historica et Archaeologica Mediaevalia, 26 (2005), Homenaje a la profesora dra. Carme Batlle i Gallart, pp. 493-513; Id., «El reino de Aragón y los conflictos mediterráneos a mediados del siglo XIV (1353-1356)», Aragón en la Edad Media, XIX (2006), Homenaje a la profesora M. Isabel Falcón Pérez, pp. 485-500.

34 ACA, Real Patrimonio, Maestre Racional, n 643, ff. 33-36.

35 Todas estas cifras proceden de las siguientes fuentes: ACA, Can., reg. 1380, ff. 76-76v (1356, nov, 21. Zaragoza) y 178-179 (1357, feb, 1. Zaragoza); ACA, Real Patrimonio, Maestre Racional, 643, ff. 3336 (1357, nov, 15. Zaragoza). M. LAFUENTE, La guerra de los Dos Pedros en Aragón, p. 664. 
en 6.000 sueldos jaqueses, que debía ser satisfecho mediante la contribución de todos los vasallos de la encomienda. Como solía ser habitual, inmediatamente después de haber recibido el donativo, el monarca emitió las correspondientes confirmaciones de privilegios y libertades a los afectados, especialmente a los vecinos de la villa, que, seguramente, la habían reclamado previamente ${ }^{36}$. Esos 6.000 sueldos pagados por los vecinos de la encomienda de la orden de Santiago en Aragón representan una pequeña parte, apenas un 3\%, de la cantidad total recaudada entre los vasallos de señorío eclesiástico en Aragón durante el primer año de la guerra, que ascendió a casi 200.000 sueldos jaqueses ${ }^{37}$.

A partir del verano de 1357, el sistema de financiación del ejército se organizó a partir de las decisiones pactadas en las Cortes, de manera que cada uno de los brazos debía hacerse cargo de proporcionar y costear una cantidad de hombres de armas, o bien únicamente de pagar el dinero equivalente a su salario. Este sistema se desarrolló en cuatro grandes ciclos fiscales, derivados de otros tantos procesos: Cortes de Cariñena de 1357 (1358-1360), Cortes de Zaragoza de 1360 (13601361), Cortes Generales de Monzón de 1362-1363 (1362-1364) y Cortes de Zaragoza de 1364 (1364-1366). Al negociar las condiciones en que debía llevarse a cabo cada servicio, los diputados se aseguraron de que Pedro IV se comprometiera a no solicitar ningún otro subsidio mientras se estuvieran recaudando los otorgados por las Cortes. Esta medida tendió a ser respetada por el rey, aunque a partir de 1361 comenzaron a ser frecuentes las solicitudes de prórrogas sobre las condiciones de los diferentes servicios.

El servicio concedido por los cuatro brazos en las Cortes de Cariñena de 1357 sirvió como modelo para los tres siguientes, tanto en lo que respecta al reparto de asignaciones sobre el total de las ayudas concedidas como a los criterios que iban a emplearse para su recaudación. En Cariñena, los representantes de los brazos del reino se comprometieron a financiar durante dos años un total de 700 hombres a caballo, que, en términos logísticos, estuvieron integrados por dos terceras partes de caballería pesada (armados) y una de caballería ligera (aforrados). Este criterio sirvió también para organizar las contribuciones dentro de cada uno de los brazos del reino, de manera que dicha relación (dos tercios de caballos armados y uno de aforrados) debía ser tenida en cuenta al expresar en moneda la asignación de un determinado número de hombres de armas.

Asimismo, la necesidad de defender el reino, que justificaba las ayudas otorgadas en estos momentos, sirvió como argumento para que las autoridades de Montalbán intervinieran directamente en la negociación del servicio. Como hemos explicado en el apartado anterior, el rey conservaba la potestad de convocar militarmente a las huestes de los lugares pertenecientes a las órdenes militares castellanas, de forma independiente a la compañía de hombres de armas vinculados

36 ACA, Can., reg. 1379, f. 162v (1357, mar, 6. Zaragoza).

37 M. LAFUENTE, La guerra de los Dos Pedros en Aragón, pp. 675-676. 
a la encomienda. Esta facultad permitió a los representantes de las villas de Alcañiz y Montalbán participar en las negociaciones como parte del brazo de las universidades reales, tanto en Cariñena como en las asambleas celebradas posteriormente ${ }^{38}$. Los representantes del brazo de la Iglesia, no obstante, mostraron una seria resistencia ante este hecho, alegando que las encomiendas de las órdenes militares debían contabilizarse, a efectos fiscales, junto al resto de los señoríos eclesiásticos ${ }^{39}$. Para solucionar este problema, se recurrió a una solución salomónica, puesta en práctica desde 1358 pero únicamente sancionada por las Cortes a partir de 1364: una mitad de la asignación cargada a la encomienda sería contabilizada como parte del servicio correspondiente a las universidades y la otra sería ingresada junto a la parte de la Iglesia. Así, en las Cortes de Zaragoza de 1360 y en las generales de Monzón de 1362-1363, las encomiendas de Alcañiz y Montalbán fueron incluidas en el brazo de las universidades ${ }^{40}$, pero de hecho continuaron contribuyendo una mitad a cada uno de los dos brazos. Esta condición contaba sin duda con la aprobación del rey, como se observa en una orden emitida desde la cancillería, en la que se obligaba a los diputados de las universidades a no reclamar en estas villas la totalidad de su aportación, una vez que habían recibido la mitad de la misma ${ }^{41}$. Finalmente, en las Cortes celebradas en Zaragoza, entre 1364 y 1365, se acordó que Alcañiz y Montalbán pagasen la mitad a cada uno de los dos brazos, lo que sucedía de hecho desde el comienzo de la guerra ${ }^{42}$.

Cuantificar las aportaciones de Montalbán y sus aldeas en los cuatro grandes ciclos fiscales derivados de las reuniones de Cortes es una labor complicada, debido en primer lugar a la escasez de referencias directas con datos precisos al respecto. El ciclo mejor documentado en este sentido es, precisamente, el primero de ellos, desarrollado como consecuencia de las Cortes de Cariñena de 1357. Durante

38 En las Cortes de Cariñena de 1357 se estableció que Montalbán y Alcañiz debían contribuir con las universidades del reino y no con los lugares de señorío eclesiástico. ACA, Can., reg. 1381, ff. 127-127v. (1358, may, 31. Gerona). Sobre la inclusión de las encomiendas de Montalbán, Alcañiz y la bailía de Monzón en el brazo de las universidades, en los servicios destinados a la defensa del reino, véase M. LAFUENTE, La guerra de los Dos Pedros en Aragón, pp. 683-684.

39 Al menos en esta primera fase de la guerra, los oficiales de Montalbán y Alcañiz eran partidarios de ser incluidos exclusivamente en el brazo de la Iglesia. Así queda implícito, por ejemplo, en una carta enviada por Pedro IV, en octubre de 1359, Juan López de Sesé, Justicia de Aragón, en la que le recordaba la causa abierta entre los procuradores del brazo de las universidades, quienes aseguraban que los vecinos de Montalbán y Alcañiz debían contribuir como parte del mismo, y los representantes de ambas villas, que afirmaban lo contrario. ACA, Can., reg. 1383, f. 95v (1359, oct, 1. Barcelona).

40 Item, ciutats et viles et lochs reyals, et en aço es entes Alcaniç et Muntalba. José María PONS GURI, Actas de las Cortes generales de la Corona de Aragón de 1362-1363, Madrid, 1982, p. 66.

41 ACA, Can., Reg. 1188, f. 138v (1363, ago, 15. San Juan de La Peña). Sobre la aplicación de esta tributación compartida, Carlos LALIENA CORBERA, Sistema social, estructura agraria y organización del poder en el Bajo Aragón en la Edad Media (siglos XII-XV), Teruel, 1987, pp. 303-304, nota 74. Durante la ejecución de lo estipulado en dichas Cortes generales, Pedro IV informó a su escribano Francisco de Castellón que la universidad de Alcañiz, por la anticipación nuevamente otorgada en Aragón, debía pagar una mitad a cada brazo. Esta mitad ascendía a 22.190 sueldos jaqueses. ACA, Can., reg. 1200, f. 677v-678. (1364, abr, 11. Montalbán).

42 Item, fue concordado por aquel acto que Alcanyz et Montalvan contribuyssen la meytat con las universidades, la otra meytat con la Yglesia. Carta LXXXIII. J.A. SESMA MUÑOZ y E. SARASA SÁNCHEZ, Cortes del reino de Aragón..., cit., p. 57. 
el periodo de vigencia del servicio pactado en esta reunión (mayo de 1358 a abril de 1360), la villa de Montalbán pagó la cantidad equivalente al salario de ocho hombres a caballo, en la proporción que indicábamos más arriba y que consistía en dos tercios según el criterio empleado para los caballos armados y uno según el asignado a los aforrados ${ }^{43}$. Teniendo en cuenta que el salario mensual estipulado en dichas cortes era de 210 y $150 \mathrm{sj}$ respectivamente ${ }^{44}$, la cifra que debía aportar la encomienda ascendía a 1.520 sueldos jaqueses al mes ${ }^{45}$. Por lo tanto, durante los dos años en los que se cobró mensualmente la ayuda, la cantidad total aportada por los vecinos de Montalbán y sus aldeas ascendió a 36.480 sueldos jaqueses.

No disponemos, por el momento, de ninguna referencia sobre las cantidades asignadas a la encomienda de Montalbán en el resto de los servicios pactados en las Cortes. Sin embargo, a partir del modelo instaurado en Cariñena y los criterios generales establecidos en cada una de las reuniones que se sucedieron entre 1360 y finales de 1365, podemos estimar con bastante precisión los compartimentos cargados sobre la villa y sus aldeas. Cabe destacar al respecto que los periodos de mayor presión fiscal se concentraron durante los trece meses en que estuvo vigente el servicio otorgado en las Cortes de Zaragoza de 1360, en las que se aplicaron las mismas pautas que en Cariñena, si bien tomando como referencia la concesión total de mil hombres a caballo en lugar de setecientos ${ }^{46}$. Durante este periodo, la tasa mensual correspondiente a Montalbán y sus aldeas se fijó, según nuestra estimación, en 2.070 sueldos jaqueses. Estos mismos criterios se desarrollaron también en el servicio otorgado en las Cortes de Zaragoza, de 1364 y la prórroga de dos meses que siguió al mismo ${ }^{47}$. La concesión de menor impacto, desde el punto de vista cuantitativo, fue la correspondiente a las Cortes generales de Monzón de 1362-1363, por la que se pagaron en Montalbán unos 1.100 sueldos en cada uno de los 31 meses durante los que se extendió el servicio ${ }^{48}$. En total, entre el comienzo del servicio concedido en Cariñena (mayo de 1358) y el final de la prórroga del subsidio otorgado en las Cortes de Zaragoza de 1364 (marzo de 1366), se pagaron en la encomienda al menos 136.910 sueldos jaqueses, cantidad

43 Así aparece reflejado en el libro de albalaes de Berenguer de Codinachs, maestre racional, correspondiente a 1365. El 1 de febrero de 1359, el rey había ordenado a Berenguer Dez Puig, portero, ir a Alcañiz, Montalbán y los lugares de la tenencia de Monroyo, para demandar la parte que les correspondía en la anticipación del citado mes. ACA, Real Patrimonio, Maestre Racional, 644, ff. 195v-196v.

44 En las actas se expresa por día: 7 sueldos jaqueses por armado y 5 por aforrado. A. SESMA y E. SARASA, Cortes del reino de Aragón, p. 29.

45 De hecho, ésta es la cantidad que fue recaudada en Montalbán por la anticipación del mes de febrero de 1359. Así consta en las notas de Juan López de Sesé, Justicia de Aragón, Jaime de Rocafort y Jaime Dez Prats sobre la administración del sueldo de los 700, por 15 meses, del 1 feb 1359 al 28 feb 1360 más la anticipación de los dos siguientes. ACA, Real Patrimonio, Maestre Racional, 784, ff. 64-67.

${ }^{46}$ El fragmento de las actas que se conserva está editado en J.A. SESMA y E. SARASA, Cortes del reino, pp. 35-42.

47 El fragmento en J.A. SESMA y E. SARASA, Cortes del reino, pp. 46-60. Las condiciones de esta prórroga en María Teresa SAUCO ÁLVAREZ, «Actas de las Cortes de Zaragoza-Calatayud. 1365-6667», Acta Curiarum regni Aragonum, t. III, Cortes de Pedro IV/2, ed. C. Laliena Corbera, Zaragoza, p. 49.

48 La concesión general establecida en esta asamblea, en José María PONS GURI, Actas de las cortes generales de la Corona de Aragón de 1362-1363, Colección de Documentos Inéditos del Archivo de la Corona de Aragón (2ª época), vol. L, Madrid, 1982, p. 61. 
que representa una tasa de exacción mensual de 1.650 sueldos, es decir, aproximadamente unos 2 sueldos 4 dineros jaqueses por fuego 49 .

Los ciclos fiscales derivados de cada una de estas negociaciones hicieron que la segunda mitad de la década de 1350 y toda la década de 1360 se convirtieran en un periodo especialmente destacado en cuanto a los niveles de exacción real. Este hecho constituyó un factor de recesión fundamental para las economías que debían satisfacer las cantidades otorgadas al rey, debido al declive demográfico y el descenso de la productividad, pero sobre todo debido a la ruptura de las condiciones que permitían la reproducción económica de la sociedad aragonesa provocada por la guerra.

\section{CONFISCACIÓN DE BIENES EN ALDEAS DE TERUEL.}

Los habitantes de la Comunidad de Teruel, territorio fronterizo con Castilla, se vieron obligados a convivir en guerra y a destinar, además de buena parte de sus excedentes, un gran número de bienes muebles al mantenimiento del ejército. Estas circunstancias provocaron que, tras la ocupación de prácticamente toda la Comunidad de Calatayud por el rey de Castilla, la recaudación de moneda topase con serias dificultades en las aldeas de Teruel, dando lugar a un problema de falta de liquidez y a unas fuertes resistencias por parte de algunos aldeanos a permitir que sus haciendas continuaran deteriorándose.

De ahí que la parte correspondiente a Teruel y sus aldeas en el subsidio concedido al rey en las Cortes de Zaragoza de 1360, se acabara cobrando mediante el embargo de bienes muebles (acémilas, ganado, harina, cereal, paños, etc), cuya venta en subasta pública debía proporcionar la cantidad asignada. Si bien no disponemos por el momento de datos que nos permitan cuantificar su aportación, conocemos algunas referencias a problemas y retrasos durante la recaudación de este compartimento en la Comunidad. Por ejemplo, sabemos que Sancho Sánchez de Borch, diputado para recaudar en Teruel y sus aldeas una parte del citado subsidio, en abril de 1361 recibió permiso de la cancillería real para forzar a realizar los pagos que se retrasaban desde el ya lejano 1 de mayo de $1360^{50}$; y que porteros

49 Véase el desglose de cada servicio en el Anexo: Tabla 5. La carga mensual la hemos establecido tomando como referencia los setecientos fuegos contabilizados en la villa durante las Cortes de Zaragoza y Calatayud de 1365, 1366 y 1367. Mํㅡ. T. SAUCO, «Actas de las Cortes de Zaragoza-Calatayud. 136566-67», p. 143. Además de los cuatro grandes ciclos derivados de las cuatro asambleas de Cortes, hemos tenido en cuenta también las ayudas concedidas por el General en octubre y noviembre de 1362. Véase al respecto M. LAFUENTE, La guerra de los Dos Pedros en Aragón, pp. 711-714. Sobre las negociaciones, la vigencia y la recaudación de todos estos servicios, así como algunos otros planteados también en las Cortes aragonesas, ibídem, pp. 229 y 676-741.

50 Concretamente, era el encargado de recoger la ayuda correspondiente a los caballeros, hidalgos e infanzones de la Comunidad, a razón de 2 sueldos jaqueses por casa y mes, durante dos años. ACA, Can., reg. 1173, ff. 159v-160 (1361, abr, 8. La Almunia). Estas ejecuciones en las propiedades de caballeros e infanzones serían interrumpidas pocos días después. ACA, Can., reg. 1175, ff. 166v-167 (1361, abr, 20. Calatayud). 
enviados bien por Pedro IV o bien por el infante Fernando (como lugarteniente general del rey en sus dominios peninsulares) estaban embargando a mediados de dicho mes distintos bienes en las aldeas, a tenor de una orden real en la que se les obligaba a no tomar más de cinco sueldos jaqueses diarios por su salario, en lugar de los siete que estaban reteniendo ${ }^{51}$. Asimismo, los hombres a pie enviados por la Comunidad al ejército y destinados en Calatayud en mayo de 1361 no habían recibido todavía ninguna de sus pagas, por lo que desde la cancillería regia se ordenó a las autoridades de la Comunidad forzar a las universidades a pagar sus salarios desde el día que hubieran partido de sus casas hasta su regreso ${ }^{52}$.

En este contexto, algunos porteros, en nombre del infante Fernando, llevaron a cabo, durante los meses de octubre y noviembre de 1362, una serie de ejecuciones entre las aldeas y términos de Teruel más próximos a Montalbán. Con la colaboración del jurado Bernad de Santa y del justicia de Montalbán, entre otros, recorrieron Las Cuevas, Perales, Martín, Vivel, La Hoz de la Vieja, Cañada Vellida, Rillo y Fuenferrada con la misión de embargar animales, alimentos, paños u otros bienes. Todos estos bienes deberían ser vendidos, a continuación, en la villa de Montalbán. Así, mientras recuas de acémilas, cabezas de ganado y otras vituallas eran sacadas de las aldeas de Teruel, algunos vecinos de Montalbán se iban preparando para adquirir en subastas públicas el género apresado.

Los porteros y comisarios encargados de la recaudación fueron Arnau Narbón y Domingo Fernández de Azuara, quienes, por instancia del infante don Fernando y tomando como centro de operaciones la villa de Montalbán, desde el 10 de octubre, procedieron a la recaudación del dinero destinado al pago de los hombres a caballo asignados a la Comunidad ${ }^{53}$. Conocemos el proceso gracias a un cuadernillo conservado en la sección de Justicia del Archivo de la Comunidad de aldeas de Teruel. Arnau Narbón y Domingo Fernández de Azuara se dirigieron a Montalbán a principios del mes de octubre de 1362, para presentarse ante el justicia de la villa con la credencial del propio infante don Fernando, por la cual se les autorizaba para tomar bienes que pertenecieran a los habitantes de Teruel o de sus aldeas allá donde éstos se encontraran ${ }^{54}$.

La investigación llevada a cabo por los delegados del infante Fernando debió ser muy meticulosa. Además de recorrer varias aldeas prendiendo mulos, asnos, cabras, ovejas o cereal que luego venderían, Arnau Narbón y Domingo Fernández

51 ACA, Can., reg. 1175, ff. 172-172v (1361, abr, 17. Calatayud).

52 ACA, Can., Reg. 1173, ff. 26-26v (1361, may, 11. Calatayud).

53 A estas alturas de la contienda, Calatayud ya había sido tomada por las tropas castellanas. Antonio GUTIÉRREZ DE VELASCO, «Las fortalezas aragonesas ante la gran ofensiva castellana en la guerra de los dos Pedros», Cuadernos de Historia Jerónimo Zurita (Zaragoza), 12-13 (1961), pp. 7-39, especialmente pp. 7-8.

54 «...bienes de aquellos do quiere que fallarlos puedan por raçon de los quales ditos vezinos e habitantes de la dita ciudat [de Teruel] e de sus aldeas son tenidas pagar por raçon del dito sueldo". El cuaderno está incompleto en sus primeros folios. Archivo de la Comunidad de aldeas de Teruel, Sección VII2, documento 2, [en adelante ACT, Sec. doc.] f. 1v (1362. Teruel). S. MARTíNEZ, La villa de Montalbán durante la baja Edad Media, pp. 133-137. 
de Azuara registraron los molinos y las casas de algunos pelaires de Montalbán para comprobar si en aquellos lugares había algún bien perteneciente a los aldeanos de Teruel. Así pues, solicitaron a Domingo Alcanadre y Domingo Segura, molineros, la notificación del dinero, ropas, animales, cereal u otros bienes de turolenses que tuvieran en su poder, a lo que respondieron que únicamente tenían un saco de harina de unas tres arrobas de capacidad, propiedad de un hombre de La Hoz de la Vieja ${ }^{55}$. El rigor y precisión en tales embargos se manifiesta en el hecho de que hasta el saco que contenía la harina fue vendido por 3 sueldos jaqueses.

Asimismo, la actividad pañera de Montalbán, que aglutinaba la pequeña y mediana producción de lanas procedentes de las aldeas próximas a la villa, fue objeto de las ejecuciones practicadas en este momento. Conocedores de las posibilidades de este sector secundario, los porteros convocaron a algunos tejedores y pelaires montalbinos para declarar bajo juramento la cantidad de paños que tenían en su poder y que pertenecían a habitantes de la Comunidad de Teruel. Solamente uno de los pelaires, Juan Sánchez Abad, confirmó la posesión de algunas piezas. Arnau Narbón, junto con el notario y los testigos pertinentes, fueron a la casa del mencionado pelaire para dar cuenta de las ropas y paños de lana que decía tener. Sin embargo, a pesar de la disponibilidad de Juan Sánchez Abad, éste no podía sino entregar una parte de aquellos paños que había declarado, ya que la mayoría se encontraban en el molino de Las Parras, donde estaban siendo abatanados ${ }^{56}$. Por ello, los comisarios apenas pudieron llevarse algunos retales por valor de 135 sueldos y 4 dineros jaqueses, con la intención de regresar al día siguiente a por el resto.

Pero enseguida los porteros se toparon con un problema importante. La tasación que el pelaire había realizado de los paños que tenía en su poder era, al parecer, demasiado elevada para la calidad y cantidad del género con el que contaba. Así que el jurado Bernat de Santa, quien había intentado vender los paños por toda la villa de Montalbán sin encontrar quién le pagara el precio convenido, llegó a un acuerdo con Juan Sánchez Abad, por el cual el pelaire debía dar a los porteros 40 sueldos para que las piezas le fuesen devueltas. Es decir, el pelaire pagó una fianza para que las piezas de lana siguieran permaneciendo en su poder, fianza que suponemos recuperaría a medida que fuera devolviendo las telas ya elaboradas a sus propietarios. La urgencia de la recaudación y los gastos propios del trabajo de los comisarios y porteros al intentar arreglar el asunto de los paños, obli-

55 «Que dineros, ropas, bestias, trigo, centeno, ordio o otras quales quiere cosas tenian en su poder que fuessen de personas de la comunidat de Teruel que aquellos lo [notificasen]. Por ello, Domingo Alcanadre e Domingo Segura dixieron por la jura que fecho avian, que no avia en poder d'ellos ni de alguno d'ellos alguna cosa que fuesse de persona ninguna de la comunidat de Terhuel, sino solament hun saquo de farina en el qual avia o pudia aver entro a tres rovas de farina de trigo, poco mas o menos, el qual era de hun hombre de la Foz e que assin les valisse Dios e aquella cruç.» Amen. ACT, Sec. VII-2, doc. 2, f. 19r (1362. Teruel).

56 «Ropas e panyos de lana, de parage o filaças que ellos o qualquiere d'ellos oviesse recebido o toviessen en su poder de qualesquiere personas de termino de Teruel». ACT, Sec. VII-2, doc. 2, ff. 33r-35r (1362. Teruel). 
garon a continuar con las ejecuciones en otro lugar, probablemente en Jarque de la Val. En cualquier caso, los habitantes de Montalbán aprovecharon la situación vivida en las aldeas de Teruel para comprar a bajo precio las posesiones embargadas a los aldeanos, contribuyendo de esa manera a solventar el pago del compartimento asignado a la Comunidad.

La recaudación de esta parte del subsidio ascendió — sin contar los 58 sueldos y 10 dineros que costó el hospedaje de los porteros, alimento de las bestias y sueldo de los acompañantes-a 1.052 sueldos y 3 dineros jaqueses, recogidos entre aldeas de la Comunidad de Teruel circundantes a la villa de Montalbán, desde donde se coordinaron las operaciones señaladas. Así, la venta de acémilas, ganados y otras pertenencias ayudaron a solventar el problema que suponía para los diputados del brazo de las universidades dicha recaudación. Posteriormente, todas las prendas que llevaron a cabo Arnau Narbón y Domingo Fernández de Azuara fueron repuestas por los regidores y administradores de la propia Comunidad ${ }^{57}$. Ya en 1369 , los representantes de la Comunidad, en presencia del lugarteniente de Berenguer de Relat, tesorero de la reina doña Leonor, expusieron entonces al procurador de las aldeas de Teruel, Guillem de Celadas, los hechos a los que nos hemos referido explicando cómo los porteros del infante don Fernando habían tomando prendas que se vendieron y cuyos propietarios, aldeanos de Teruel, nunca cobraron y ahora pedían que se retribuyeran. Esta devolución trataba de convertir las confiscaciones sobre bienes de particulares en un gasto común, cuyo coste quedaría pues integrado en los presupuestos ordinarios de la Comunidad ${ }^{58}$.

\section{DEFENSA Y FORTIFICACIÓN DE LA VILLA}

A lo largo de la Baja Edad Media, y especialmente durante periodos de guerra, la reparación de las fortificaciones era una necesidad ineludible, cuyo ordenamiento recaía generalmente en manos de sus propios alcaides ${ }^{59}$. El cuidado en el

57 ACT, Sec. V-2, doc. 7 (1369, mar, 6. Teruel).

58 Para conocer sus incidencias, aparte del listado entregado por los diputados de las aldeas con los afectados por los embargos, contamos con algunos albaranes que atestiguan el reembolso de las cantidades reportadas con la venta de tales prendas certificadas por los concejos de aquellos lugares de donde eran vecinos los afectados. Así, el 13 de abril de 1369, Juan de Torres recibió del procurador de las aldeas los 160 sueldos que se le debían por los dos mulos que se vendieron en la villa de Montalbán a Vicente Pascual. ACT, Sec. IV-2.5, doc. 4.863 (1369, abr, 13. Teruel). En otras ocasiones no eran ya los propios afectados sino sus herederos los que recibían las devoluciones. El 15 de junio de 1369, Pascuala, vecina de Cañada Vellida, recibe 50 sueldos jaqueses que a Domingo Lope, su marido, mandaron dar por una bestia que le apresaron en la villa de Montalbán. ACT, Sec. IV-2.5, doc. 4.869 (1369, jun, 15. Celadas). El 16 de octubre de ese mismo año, Domingo de Arcos, vecino de Martín del Río, recuperaba los 34 sueldos que se obtuvieron con la venta de un asno y una asna que le pertenecían, así como otros 10 sueldos de otro asno, que había pertenecido a su hijo Juan Galindo, ya difunto, y que entregaba a su nieta María. ACT, Sec. IV-2.5, doc. 4.871 (1369, oct, 16. S.L.).

59 La gestión y el mantenimiento de las fortificaciones en la baja Edad Media, especialmente de aquellas ubicadas en villas y ciudades, es una línea de investigación magistralmente tratada por la historio- 
desarrollo de las obras era una cuestión de vital importancia, dado que de su buen término dependía la seguridad de la población. Por ello, durante la guerra con Castilla existieron algunas directrices generales dirigidas desde el poder real, con el fin de asegurar tanto la defensa de la frontera y del territorio, como el control sobre el mismo.

Una de las primeras órdenes emitida en relación con el buen estado de las murallas de Montalbán, es la que dirigió Pedro IV, en marzo de 1357, al procurador de la villa, Rodrigo de Altabás. En ella le recordaba que los habitantes de la villa y sus aldeas debían ocuparse de fortificar y reparar los muros urgentemente, debido a la guerra declarada por el rey de Castilla ${ }^{60}$. Un año después, en febrero de 1358 , el Ceremonioso se dirigía de nuevo al citado procurador, comunicándole que el muro y los fosos de la villa necesitaban algunas reparaciones urgentemente ${ }^{61}$. Además, le recomendaba que, en caso de necesitarlo, forzase a los habitantes de la villa y de sus aldeas a trabajar en las obras ${ }^{62}$, así como a derribar cualquier construcción que pudiera suponer un impedimento para la realización de las mejoras en los muros ${ }^{63}$. Tales obligaciones iban a convertirse, enseguida, en un motivo de confrontación entre los delegados del rey y los propios vecinos.

A finales del año 1362, Pedro IV se dirigía a dos vecinos de Montalbán, Miguel Navarro y Pedro Martínez de la Blanca, quienes habían sido excusados de servir con la hueste un año antes. El motivo de la misiva no era otro que hacer notar la importante necesidad de que los muros de la villa estuviesen bien provistos. Para ello, los nombraba obreros y los dotaba de las competencias necesarias para en-

grafía portuguesa. Entre los numerosos ejemplos, João Gouveia, MONTEIRO, Os castelos portugueses dos finais da Idade Média: presença, perfil, conservaçao, vigilância e comando, Lisboa, 1999. Entre los estudios más recientes dedicados a fortificaciones aragonesas, María Luz, RODRIGO ESTAVAN, «Torres, castillos y murallas en la frontera con Castilla. Notas sobre el sistema defensivo darocense (siglos XIV y XV)», El Ruejo (Daroca), 4 (1998), pp. 71-106; Germán NAVARRO ESPINACH y Julian M. ORTEGA ORTEGA, «Las cuentas de la reparación del castillo de Miravete de la Sierra (1458-1461)», Studium. Revista de Humanidades (Teruel), 6 (1999), pp. 241-275; y José Manuel ABAD ASENSIO «Castillos del alto Jiloca: un documento sobre su reparación en la segunda mitad del siglo XIV», en $A c$ tas del III Congreso de Castellología Ibérica, Guadalajara, 2005, pp. 255-272.

60 ACA, Can., reg. 1152, f. 106v (1357, mar, 24. Zaragoza), ACA, Can., reg. 1150, f. 213v (1357, dic, 10. Magallón).

61 ACA, Can., reg. 1381, f. 106v (1358, feb, 12. Valencia).

62 Los fueros del reino obligaban a la población a contribuir con una exacción especial o a través de su propio servicio. Construcción, mantenimiento y reparación de fosos y murallas. 278a (en otras f. 35). Jaime Primero. En Huesca, 1247. En P. SAVALL y S. PENÉN, Fueros, observancias y actos de corte, p. 149. Sobre la mano de obra en obras de fortificación son interesantes los casos estudiados en Asunción VALENZUELA GONZÁLEZ, «Algunos datos sobre la reconstrucción de castillos en las merindades de Tudela y Sangüesa, 1360-1362», Príncipe de Viana. Anejo 8. Primer Congreso General de historia de Navarra, Pamplona, 1988, t. 3, pp. 657-667; e Itziar MUÑOZ Y CASCANTE, «Mano de obra femenina en las obras del castillo de Arguedas (1385)», Príncipe de Viana. Anejo 8, cit., t. 3, pp. 559-563.

63 Este es uno de los aspectos que mayores impedimentos pusieron al desarrollo de las obras de fortificación de villas y ciudades. El derribo de edificios fue una necesidad para los directores de las reparaciones, puesto que la existencia de viviendas o dependencias adosadas a la muralla suponía un impedimento para la defensa, ya que se con ello se exponían a un grave peligro y se facilitaba el asalto del enemigo. La polémica en las villas por la demolición de algunos edificios supusieron en muchas ocasiones la paralización de las obras y la intervención real para intermediar entre los afectados y los encargados de llevarlas a cabo. M. LAFUENTE, «Comportamientos sociales ante la violencia», pp. 249-254. 
cargarse de la dirección de las obras, para forzar a las personas de la villa a colaborar en las tareas de fortificación, para obligarlas a contribuir económicamente según su criterio y también para aplicar las penas correspondientes a quienes pusiesen algún impedimento al desarrollo de sus funciones ${ }^{64}$.

Otra de las razones para la reparación de las fortificaciones era la necesidad de preparar un espacio que sirviera como refugio. De ahí que una de las disposiciones básicas de estos mandatos fuera aprovisionar las villas amuralladas y castillos con los víveres suficientes como para que los que allí se recogieran pudieran subsistir durante algún tiempo, en caso de ser sometidos a un asedio. Las posibilidades de que el ejército enemigo invadiese la comarca de Montalbán, a partir de los primeros meses de 1363, fueron cada vez mayores, dado que los movimientos de los castellanos, con la ocupación de Tarazona y Calatayud, habían definido una nueva frontera de la que Montalbán formaba parte junto con Daroca y Teruel. En marzo de 1363, el Ceremonioso comunicaba a su consejero García López de Sesé la necesidad de reforzar el castillo de Montalbán, a instancias del comendador Fernando Gómez de Albornoz y los hombres buenos de la villa, solicitándole que acudiese allí para dirigir las reparaciones necesarias dentro del castillo y abastecerlo de alimentos y otros bienes. Además, era conveniente levantar algún tipo de amurallamiento interior y construir una pequeña fortaleza dentro de la villa, aunque para ello fuera necesario derribar alguna casa ${ }^{65}$. Esto significaría que en caso de asedio todos los habitantes de las aldeas podrían refugiarse en el interior de la muralla, y en caso de ocupación de la villa, tendrían una segunda oportunidad de resistir en el castillo del comendador.

La necesidad de mantener provistos los castillos para garantizar la protección de las personas que habitaban las aldeas y que estaban, en consecuencia, más expuestas al ataque de los enemigos y al paso de compañías militares, justificó la orden dada por el rey a García López de Sesé, para que todos los aldeanos de Montalbán, Teruel, Daroca y Huesa acudiesen a refugiarse a las fortalezas correspondientes a cada uno de ellos, porque trobarian alli por panes e vino e otro refrescamiento, procedentes de las mismas aldeas. Además, se establecieron entonces medidas drásticas para aquellos que desobedecieran las órdenes de abandonar las casas y dirigirse a las fortalezas: pérdida de bienes, mutilación de miembros o pena de muerte ${ }^{66}$.

64 «Algunos hombres d'aquella villa no han querido consentir que los ditos muros e vallas se fagan.» ACA, Can., reg. 1385, ff. 93-93v (1362, dic, 19. Monzón).

65 ACA, Can., reg. 1384, ff. 181-181v (1363, mar, 5. Monzón). También en A. GUTIÉRREZ, «Las fortalezas aragonesas», p. 21. Según este autor, la instrucción recibida por García López de Sesé y su intervención en la villa de Montalbán venían derivadas por alguna desavenencia entre el comendador y los vecinos de la villa, por lo que se encontró con dificultades en el caso de tener que acomodar a los habitantes en la fortaleza. De ahí, tal vez, la necesidad de realizar una pequeña fortificación en el interior del entramado urbano.

66 ACA, Can., reg. 1384, f. 182 (1363, mar, 5. Monzón). A. GUTIÉRREZ, «Las fortalezas aragonesas», p. 21. ACA, Can., reg. 1384, f. 182v (1363, mar, 5. Monzón). Del mismo modo, se hacía entrega de 500 sueldos para la reparación y abastecimiento del castillo. 
Tras la ocupación de Teruel, en la primavera de 1363, la frontera sufrió una alteración sustancial que convirtió a Daroca y Montalbán en cabeceras de la resistencia en la mitad sur del reino de Aragón. La reorganización del frente requería el desplazamiento de gentes y hombres de armas hacia el interior, en busca de plazas que contaran con la infraestructura suficiente como para garantizar su seguridad. En este contexto, el noble Pedro Fernández, señor de Híjar, fue destinado a la villa de Montalbán por orden del rey con el encargo de organizar su defensa ${ }^{67}$. Cuando el señor de Híjar llegó a Montalbán, las obras y disposiciones llevadas a cabo por García López de Sesé se encontraban paralizadas por motivo de un enfrentamiento entre el comendador y los hombres de la villa. La discrepancia sobre el desarrollo de las obras, que implicaban modificaciones del entramado urbano y la reutilización de espacios en las dependencias del castillo de la encomienda, así como las severas medidas tomadas en caso de desobediencia a tales disposiciones, junto al derribo de edificios para facilitar las obras, llevaron a los habitantes de Montalbán a enfrentarse al comendador. Para solucionar el problema, el rey ordenó a Pedro Fernández de Híjar resolver la question sobre las obras del castiello e de los muros de la dita villa, por la qual contienda cessa las ditas obras, de la qual cosa se poria seguir gran danyo, lo que Dios no quera ${ }^{68}$.

Más adelante, en el otoño de 1364, el rey dio algunas instrucciones al gobernador general, Jordán Pérez de Urriés, sobre la fortificación del castillo de Montalbán. Para financiar las obras, se contaba en primer lugar con la contribución obligatoria de todos aquellos que fueran a utilizar el castillo para refugiarse y, sobre todo, con el dinero procedente de la venta de primicias, durante los dos próximos años, de la villa de Montalbán y sus aldeas junto a las de localidades como La Hoz de la Vieja, Obón, Abanto, Oliete, Montón, Ejulve, La Zoma y el lugar de Peña del $\mathrm{Cid}^{69}$. Unas semanas después de haber recibido el gobernador estas instrucciones, los habitantes de La Hoz de la Vieja, quienes estaban obligados a refugiarse en Montalbán y por ello debían contribuir en las obras, recurrieron al rey explicándole que en su propia villa existía un castillo fuerte que estaban dispuestos a reparar y a utilizar como refugio. Por ello, Pedro IV les concedió una revocación de la carta anterior, circunstancia que tuvo como consecuencia la paralización de las obras de Montalbán. Pero, o bien la defensa de La Hoz no era tan segura como sus habitantes creían, o éstos simplemente habían utilizado una estrategia para verse liberados de contribuir en las obras de Montalbán. En cualquier caso, en febrero del año siguiente, el rey volvió a enviar las instrucciones iniciales al gobernador ge-

67 ACA, Can., reg. 1191, f. 564 (1363, oct, 8. Barbastro).

68 ACA, Can., reg. 1193, f. 5v (1363, dic, 19. Lérida).

69 Las primicias fueron uno de las fuentes de renta eclesiásticas a las que recurrió la monarquía y su destino prioritario fueron las obras de fortificación. Un estudio sistemático de la financiación de este tipo de obras en Francia durante la baja Edad Media, en A. RIGAUDIÉRE, «Le financement des fortifications urbaines en France du milieu du XIV siècle à la fin du XV siècle», en Gli aspetti economici della guerra in Europa, secc. XIV-XVIII, Atti della Sedicesima Settimana di Studi, e. S. Cavaciocchi, Prato, 1984, ed. en CD-rom. Véase también María Luisa LEDESMA RUBIO, «El uso de las primicias eclesiásticas por los monarcas aragoneses en la segunda mitad del siglo XIV», Simposio Nacional sobre Ciudades Episcopales, Zaragoza, 1986, pp. 61-67. 
neral, en las que la población de todos los lugares mencionados debería participar económicamente o mediante su trabajo, además de contar con el dinero de la venta de las primicias de cada lugar durante los dos años siguientes ${ }^{70}$.

\section{CONCLUSIONES}

El estudio de las implicaciones sociales y económicas de Montalbán en la estructura militar del reino, desde el comienzo de la guerra de los Dos Pedros hasta el final de la guerra civil castellana, nos ha permitido observar algunas pautas comunes al resto de la sociedad aragonesa, especialmente en lo que respecta a las aportaciones de combatientes y recursos, así como a la resolución de problemas derivados de los procedimientos empleados en cada caso. Pero más allá de las circunstancias compartidas o las consecuencias generales del conflicto, en el caso de Montalbán hemos podido desvelar algunas particularidades derivadas de su condición jurisdiccional.

En primer lugar, hemos comprobado que el comendador de Montalbán estaba obligado a mantener disponibles permanentemente con las rentas de la encomienda a veinte hombres de armas, con los que debía ponerse al servicio del rey en el caso de que éste lo convocase para ello. No obstante, durante la guerra con Castilla, las compañías dirigidas por los comendadores, Juan Jiménez de Urrea y Fernando Gómez de Albornoz, estuvieron integradas por una cantidad variable de hombres a caballo, casi siempre superior a la cifra mencionada anteriormente. Este hecho se debió tanto a factores puramente logísticos como a la integración en dichas compañías de hombres vinculados a los linajes Urrea y Albornoz, aunque no tuvieran relación directa con la orden de Santiago. Por otro lado, la potestad regia de convocar militarmente a las huestes de los concejos de algunos señoríos de órdenes militares, significó que los oficiales de Montalbán hubieron de movilizar regularmente una serie de hombres a pie, equipados con ballestas o lanzas, que sirvieron generalmente a las órdenes del comendador. El número de miembros de la hueste de Montalbán, así como las cantidades a percibir por éstos, osciló en función de las necesidades de cada momento y de la disponibilidad de recursos en la villa. Asimismo, hemos podido documentar algunas de las circunstancias de exención de servicio militar en el caso de convocatoria general, especialmente aquella que permitía a los oficiales del concejo y a algunos vecinos quedar al margen de tal obligación.

Respecto al impacto económico de la guerra, nuestra investigación se ha centrado principalmente en definir los criterios de la exacción y, asimismo, en cuantificar las cantidades recaudadas en la villa. En este sentido, hemos comprobado que durante el primer año de la guerra (aproximadamente entre el verano de

70 ACA, Can., reg. 1386, ff. 131v-132. (1364, oct, 28. Montalbán). Durante la ocupación castellana del territorio fronterizo y de buena parte de las Comunidades de Calatayud, Daroca y Teruel, no fue posible la recaudación de primicias ni la de ningún otro impuesto. 
1356 y la celebración de las Cortes de Cariñena) los vecinos de Montalbán pagaron al menos un subsidio al rey, negociado por el comendador en marzo de $1357 \mathrm{y}$ tasado en 6.000 sueldos jaqueses. Asimismo, en dicho periodo, la aljama de judíos de la villa contribuyó en las dos demandas solicitadas sucesivamente por el rey a una larga serie de aljamas de todo el reino, pagando en total una cantidad próxima a los 1.000 sueldos.

Para los compartimentos asignados en las Cortes, hemos trabajado a partir del modelo documentado para el periodo 1358-1360, que nos ha permitido plantear una estimación sobre las cantidades pagadas en la villa y sus aldeas en cada ciclo fiscal hasta el principio de la guerra civil castellana. El ejercicio de la capacidad de convocatoria militar directa al concejo de Montalbán, en condiciones idénticas a los lugares de realengo, condicionó también la forma en que se iban a desarrollar los servicios asignados a la villa y sus aldeas por las Cortes del reino. Dado que, desde las Cortes de Cariñena de 1357 en adelante, dichos servicios se iban a otorgar con el fin de defender el reino y se iban a repartir en hombres a caballo, Montalbán y sus aldeas iban a ser incluidas en el brazo de las universidades reales. Pero, en la práctica, esta condición no se llegó a aplicar en ningún momento entre 1357 y 1364, a pesar de ser confirmada en cada una de las reuniones de Cortes, sino que de hecho tanto Montalbán como Alcañiz repartieron sus contribuciones en dos mitades, una integrada en el compartimento tocante al brazo eclesiástico y la otra al de las universidades. Esta circunstancia se debió a que, desde el inicio de la guerra, los diputados de la Iglesia contaron a ambas encomiendas entre sus propios lugares, es decir, junto a aquellos entre los que repartir la parte del subsidio correspondiente al brazo eclesiástico. Sólo en las Cortes de Zaragoza de 1364 se dotaría de legalidad este particular reparto, medida que, por alguna razón que se nos escapa, fue intensamente protestada por los vecinos, según quedó reflejado en los agravios presentados a las cortes de $1371-1372^{71}$. Las cantidades pagadas durante la ejecución de cada uno de los grandes ciclos fiscales derivados de las reuniones de Cortes, entre mayo de 1358 y marzo de 1366, sumaron en Montalbán y sus aldeas un total de aproximadamente 136.000 sueldos jaqueses, que, como hemos indicado en el tercer apartado del trabajo, significaron una tasa de exacción mensual de unos 1.650 sueldos jaqueses, es decir, unos 2 sueldos 4 dineros jaqueses por vecino y mes.

Los procedimientos concretos de recaudación de todos estos compartimentos han quedado, sin embargo, fuera de nuestro ámbito de estudio debido a la escasez de referencias al respecto. Hasta que el tema de las imposicions sea abordado directamente por los historiadores dedicados a la Edad Media aragonesa, únicamente podemos señalar que, durante la guerra de los Dos Pedros, la tónica do-

71 Carlos LALIENA CORBERA, Mำ Teresa IRANZO MUÑíO y Sergio MARTÍNEZ GARCÍA, «Actas del proceso de Cortes de Caspe, Alcañiz y Zaragoza. 1371-1372», Acta Curiarum regni Aragonum, t. III, Cortes de Pedro IV/2, ed. C. Laliena Corbera, Zaragoza, p. 463. 
minante fue la aplicación de formas de fiscalidad directa, a partir de fogajes, en los que cada unidad fiscal debería contribuir en relación con el valor de sus bienes.

Por último, hemos constatado una intensa relación de la encomienda de Montalbán con la Comunidad de aldeas de Teruel, por ejemplo, al convertirse en el centro donde fueron subastados algunos de los bienes embargados en algunas aldeas turolenses, a causa de las deudas contraídas en el pago de algunos compartimentos. Los procesos de ejecución en bienes de las faltas en los plazos de los subsidios concedidos al rey son todavía mal conocidos, ya que el carácter local de la documentación que sin duda los recogió ha dificultado su conservación. Por ello, el caso que hemos presentado aquí es excepcional. Por otro lado, la estrecha relación entre los vecinos de Montalbán y la Comunidad de Teruel se puso de manifiesto también a la hora de fortificar y defender la villa, ya que tras la conquista de la ciudad por el ejército castellano, en 1363, el castillo de la encomienda se convirtió junto a Daroca en una de las plazas fuertes más importantes entre las situadas al sur de Zaragoza.

\section{ANEXO}

Tabla 1. Solicitudes de hombres a caballo a los comendadores de Montalbán (1269-1341)

\begin{tabular}{|c|c|c|c|}
\hline Campañas & Año & Comendadores & Hombres solicitados \\
\hline Cruzada a Tierra Santa & 1269 & $\begin{array}{c}\text { Gonzalo Rodríguez } \\
\text { Girón }\end{array}$ & 20 \\
\hline $\begin{array}{c}\text { Defensa de Valencia ante la } \\
\text { Unión }\end{array}$ & 1282 & $\begin{array}{c}\text { Rodrigo Jiménez de } \\
\text { Luna }\end{array}$ & 10 \\
\hline Guerra contra Granada & 1303 & - & $20^{72}$ \\
\hline Conquista de Cerdeña & 1323 & - & 10 \\
\hline Expediciones contra Granada & 1329 & Vidal de Vilanova & 5 \\
\cline { 2 - 4 } & 1330 & & 0 \\
\cline { 2 - 4 } & 1330 & & $20^{73}$ \\
\cline { 2 - 4 } & 1332 & & \\
\hline
\end{tabular}

72 El resto de los efectivos solicitados por Jaime II a las órdenes militares, en este contexto, se fijaron en 100 hombres a la Orden del Temple, 60 a la del Hospital y 30 a la de Calatrava. Enrique RODRÍGUEZ-PICAVEA MATILLA, Los monjes guerreros en los reinos hispánicos. Las órdenes militares en la Península Ibérica durante la Edad Media, Madrid, 2008, pp. 138-139.

73 Conmutados por 10.000 sueldos reales de Valencia. 


\begin{tabular}{|c|c|c|c|}
\hline Campañas & Año & Comendadores & Hombres solicitados \\
\hline Guerra contra Marruecos & 1339 & Vidal de Vilanova & 15 \\
\cline { 2 - 4 } & 1339 & & $10^{74}$ \\
\cline { 2 - 4 } & 1341 & & $15^{75}$ \\
\hline
\end{tabular}

Fuentes: R. SÁINZ, La orden de Santiago, pp. 65, 77 y 85; Id., La orden de Santiago (II), pp. 60-63 y 65-66; ACA, Varia de Cancillería, 416, ff. 11-14; y M. SÁNCHEZ MARTíNEZ, "Las órdenes militares en la cruzada granadina de Alfonso el Benigno (1329-1334)", Anuario de Estudios Medievales (Barcelona), 28 (1998), pp. 31-58, concretamente pp. 53-55.

\section{Tabla 2. Compañía del comendador de Montalbán (con el infante Fernando), en Zaragoza, 30 de enero de 1363. 14 hombres a caballo}

\begin{tabular}{|c|c|}
\hline Propietarios de caballos armados (9) & Propietarios de cab. aforrados (5) \\
\hline Berlanga, Alfonso de & Calvo, Pedro de \\
Bernat, Guillem & Cornudiella, Gombalt de \\
Fernández de Cuenca, Juan & Pérez de la Figuera, Juan \\
Fernández de Molinacueva, Juan & Salvador, Pedro \\
Fernández, Diego & Sánchez de Fuentesclaras, Juan \\
Gómez de Albornoz, Fernando, comendador & \\
Martínez de Cuenca, Sancho & \\
Pérez de Beztant, Ruy & \\
Rodríguez, Gonzalo & \\
\hline
\end{tabular}

Fuente: ACA, Real Patrimonio, Maestre Racional, 2498, ff. 6-6v.

${ }^{74}$ En esta convocatoria, la relación de efectivos a caballo solicitada a las órdenes por Pedro IV quedaba de la siguiente forma: 85 a la orden del Hospital, 50 a la de Montesa y 30 a la de Calatrava, además de los 10 solicitados a la de Santiago. Carlos DE AYALA MARTíNEZ, Las Órdenes militares hispánicas en la Edad Media (siglos XII-XV), Madrid, 2003, p. 555.

75 Esta cifra contrasta con el número de hombres solicitados al resto de las órdenes militares, ya que el castellán hospitalario de Amposta debía enviar 70, la orden de Montesa 60, el resto de lugares del Hospital 40 y la de Calatrava 30. E. RODRÍGUEZ-PICAVEA MATILLA, Los monjes guerreros, cit., pp. 138-139. 
Tabla 3. Compañía del comendador de Montalbán, de la orden de Santiago, ante la Puerta Cremada de Zaragoza, 12 de junio de 1363. 52 hombres a caballo

\begin{tabular}{|c|c|}
\hline Propietarios de caballos armados (34) & Propietarios de cab. aforrados (18) \\
\hline $\begin{array}{c}\text { Arcayne, Juan de } \\
\text { Bernat, Guillem } \\
\text { Castro, Ato de } \\
\text { Cornoduella, Gombalt de } \\
\text { Fernández de Soria, Juan } \\
\text { Fernández, Gonzalo } \\
\text { Fernández, Juan } \\
\text { Fernández, Pedro } \\
\text { Fernández, Unyo } \\
\text { García, Álvaro } \\
\text { García, Pedro } \\
\text { Gea, Pedro } \\
\text { Gómez de Albornoz, Fernando, } \\
\text { comendador } \\
\text { González, Fernando } \\
\text { Grisén, Blasco } \\
\text { Jiménez, Fernando } \\
\text { Jiménez, García } \\
\text { Lisón, Francés de } \\
\text { López, Martín } \\
\text { López, Sancho } \\
\text { Martínez de Serón, Pedro } \\
\text { Martínez, Sancho } \\
\text { Mogany, Simón de } \\
\text { Nariz, Jimeno de } \\
\text { Nariz, Martín de } \\
\text { Nariz, Pedro de } \\
\text { Oriella, Miguel } \\
\text { Pérez de Bastay, Ruy } \\
\text { Rodríguez, Gonzalo } \\
\text { Roldán, Lorenzo } \\
\text { Ruiz, Alfonso } \\
\text { Sesé, Miguel de }\end{array}$ & $\begin{array}{c}\text { Aladrén, Miguel de / no recibido } \\
\text { Alfocea, García de } \\
\text { Arnalt de Arándiga, Pedro } \\
\text { Díez, Álvaro } \\
\text { Esteban, Pedro } \\
\text { Fernández de Parentona, Juan } \\
\text { Fernández, Juan } \\
\text { Fernández, Lope } \\
\text { Ferrando, Alfonso } \\
\text { Funes, Ramiro de } \\
\text { Galíndez de Ortiz, Juan } \\
\text { Garcés, Martín } \\
\text { Longares, Juan de } \\
\text { Martínez, Jimeno } \\
\text { Oriella, Sancho } \\
\text { Sánchez, Miguel } \\
\text { Sayas, Juan de } \\
\text { Taris, Martín }\end{array}$ \\
\hline
\end{tabular}

Fuente: ACA, Real Patrimonio, Maestre Racional, 2498, ff. 66v-67. 
Tabla 4. Compañía de Fernando Gómez de Albornoz, comendador de Montalbán, en Barcelona, 24 de noviembre de 1363. 35 hombres a caballo

\begin{tabular}{|c|c|}
\hline Propietarios de caballos armados (17) & Propietarios de cab. aforrados (18) \\
\hline Álvarez, Fernando & Aris, Ferrán de \\
Álvarez, Juan & Diego Hernández, Pedro \\
Fernández, Gómez & Díez, Fernando \\
Fernández, Nuño & Fernández, Alfonso \\
Hernández de Molina Cova, Juan & García, Juan \\
Hernández, Domingo & Gonzalo \\
Luengo, Lorenzo & Hernández, García \\
Martínez, Juan & Hernández, Juan \\
Martínez, Sancho & Hernández, Pedro \\
Muñoz, Juan & Hernández, Pedro \\
Ortiz, Martín & Hernández, Pedro \\
Rodríguez, Ferrán & Martínez, Antón \\
Ruiz, Alfonso & Martínez, Pedro \\
Ruiz, Martín & Pérez, Gonzalo \\
Sánchez de Ordeñada, Juan & Rodrigo \\
Sánchez, Lope & Sánchez, Gonzalo \\
Suárez, Men & Sánchez, Martín \\
& Sánchez, Miguel \\
\hline
\end{tabular}

Fuente: ACA, Real Patrimonio, Maestre Racional, 2497, s/n.

Tabla 5. Cantidades pagadas por los vecinos de Montalbán en los ciclos fiscales derivados de las reuniones de Cortes (mayo 1358-marzo 1365)

\begin{tabular}{|c|c|c|c|}
\hline Servicio & HC / coste mensual (sj) & Vigencia (meses) & Coste total (sj) \\
\hline Cariñena 1357 & $8 / 1.520$ & 24 & 36.480 \\
\hline Zaragoza 1360 & $11 / 2.070$ & 13 & 26.910 \\
\hline Zaragoza 1362 & $8 / 1.440$ & 2 & 2.880 \\
\hline Monzón 1362-63 & $-/ 1.100$ & 31 & 34.100 \\
\hline
\end{tabular}


Ejército y fiscalidad en la encomienda santiaguista de Montalbán (Aragón)...

\begin{tabular}{|c|c|c|c|}
\hline Servicio & HC / coste mensual (sj) & Vigencia (meses) & Coste total (sj) \\
\hline Zaragoza 1364 & $11 / 2.070$ & 14 & 28.980 \\
\hline Zaragoza 1365 & $11 / 2.070$ & 2 & 4.140 \\
\hline Zaragoza 1365 & $9 / 1.710$ & 2 & Total \\
\hline \multicolumn{4}{|r|}{} \\
\hline $\begin{array}{l}\text { HC: hombres a caballo } \\
\text { sj: sueldos jaqueses }\end{array}$
\end{tabular}


